THE COSTS AND RISKS OF BROWNFIELD REDEVELOPMENT VERSUS GREENFIELD DEVELOPMENT: A PRIVEAT SECTOR PERSPECTIVE ON THE EFFECTIVENESS OF COMMUNITY INCENTIVE PACKAGES. A CASE STUDY OF WATERLOO, ONTARIO

by

Brandon Green, BSc (Honours), University of Toronto, 2012

A Professional Project Paper Presented to Ryerson University in partial fulfilment of the requirements for the degree of

Master of Applied Science

In the Program of

Environmental Applied Science and Management

Toronto, Ontario, Canada, 2016

CBrandon Green, 2016 
Author's Declaration

I hereby declare that I am the sole author of this Professional Project Paper. This is a true copy of the Professional Project Paper, including any required final revisions. I authorize Ryerson University to lend this Professional Project Paper to other institutions or individuals for the purpose of scholarly research. I further authorize Ryerson University to reproduce this Professional Project Paper by photocopying or by other means, in total or in part, at the request of other institutions or individuals for the purpose of scholarly research. I understand that my Professional Project Paper may be made electronically available to the public. 


\title{
THE COSTS AND RISKS OF BROWNFIELD REDEVELOPMENT VERSUS GREENFIELD DEVELOPMENT: A PRIVEAT SECTOR PERSPECTIVE ON THE EFFECTIVENESS OF COMMUNITY INCENTIVE PACKAGES. A CASE STUDY OF WATERLOO, ONTARIO
}

Master of Applied Science, 2016

\section{Brandon Green}

\section{Environmental Applied Science and Management}

\section{Ryerson University}

\begin{abstract}
Traditionally, there has been minimal interest on behalf of developers, land owners as well as private sector stakeholders to redevelop brownfields (De Sousa, 2000). The fears of real or perceived contamination have made the redevelopment project too expensive and risky to develop profitably. Limited government funding and assistance to the private sector for brownfield redevelopment further complicates brownfield redevelopment. This research investigated Ontario's Community Im provement Plans with brownfield provisions and how they quantitatively aid investor returns. Hypothetical scenarios for a multifamily residential development were generated for both hypothetical brownfield and greenfield sites where brownfield incentives could be implemented. The pro forma analysis revealed that a full exemption from regional development charges (RDC) had the greatest effect on investor returns (NPV and IRR) followed by the joint TIEG offered in the City of Waterloo. Greenfield development is the most financially feasible option with no added costs or risks from contamination.
\end{abstract}


Acknowledgments

I would like to dedicate this research to my parents. 


\section{Table of Contents}

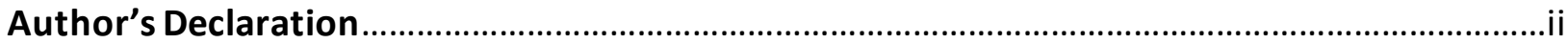

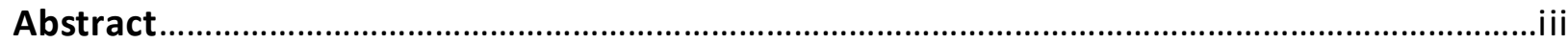

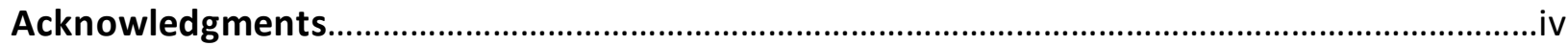

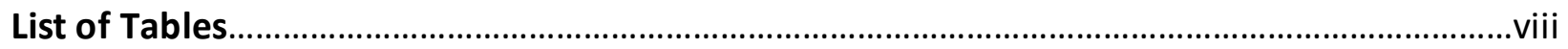

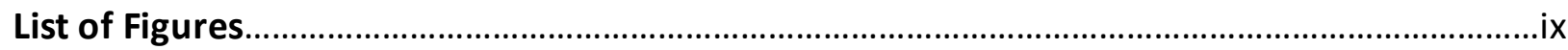

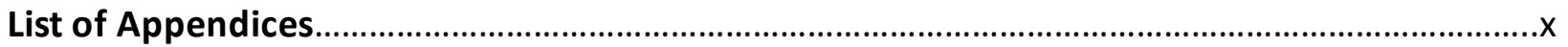

\section{Chapter 1 - Introduction}

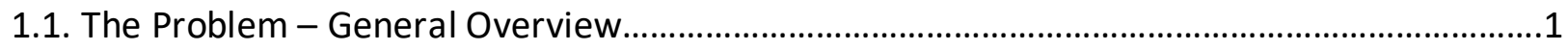

1.2. What is the Significance of Brownfields? Why is Brownfield Remediation Important............3

1.3. (Roadblocks and) Deterrents to Brownfield Redevelopment...............................................4

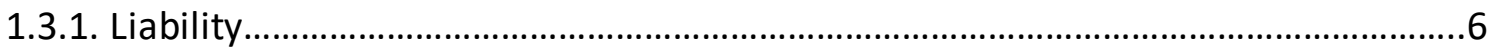

1.3.2. Cost and Time

1.3.3. Lack of Government Incentives and Fragmented Regulatory Policy.........................8

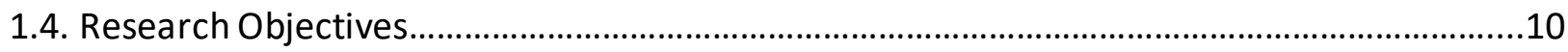

\section{Chapter 2 - Literature Review}

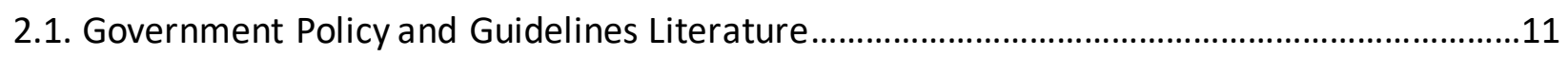

2.1.1. Establishing National Guidelines and Programs for Contaminated Sites................11

2.1.2. Establishing Provincial Guidelines and Programs for Contaminated Sites...............13

2.1.3. Brownfield Regulation in Ontario............................................................................14

2.2. Brownfield Remediation - Sustainable Growth Measures..................................................16

2.2.1. Brownfield Remediation - Sustainable Growth Ontario.......................................16

2.2.2. Local Policy for Brownfield Redevelopment - Sustainable Growth Waterloo........17

2.3. Brownfield Remediation - Scientific Literature .....................................................................18

2.4. Problems to Brownfield Remediation - Parent Study and Filling in the Gaps.......................20

Chapter 3 - Incentive Packages 


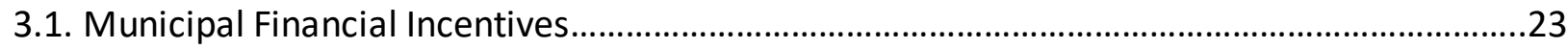

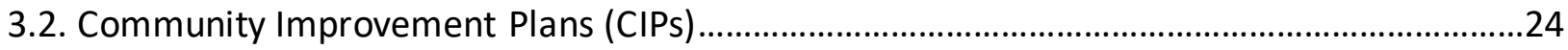

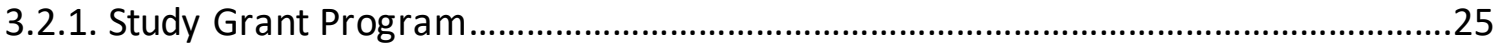

3.2.2. Rehabilitation and Redevelopment Grants / Loans..............................................26

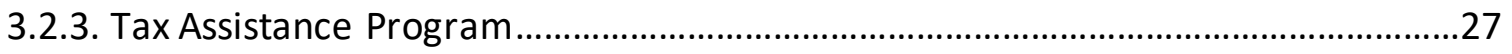

3.2.4. Tax Increment Equivalent Grants (TIEGs) ..........................................................28

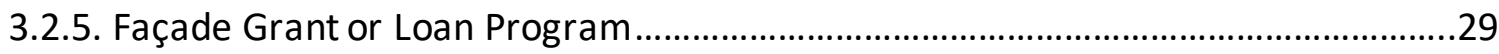

3.2.6. Municipal Fees Grant Program ..............................................................................29

3.2.7. Development Charge Reductions or Exemptions and Equivalent Offsets...............30

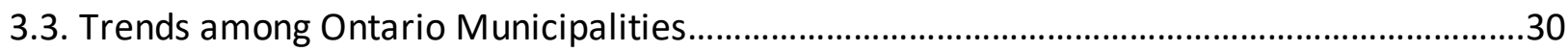

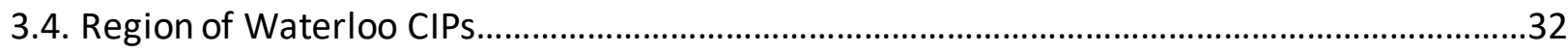

\section{Chapter 4 - Market Analysis / Marketability Study}

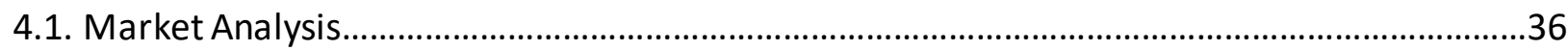

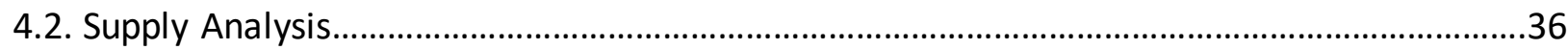

4.2.1. Inventory and Quality of Existing and Future Multifamily Development.................37

4.2.2. National and Region-wide Investment into Multifamily Development....................38

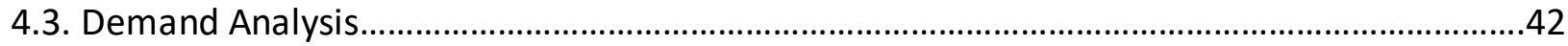

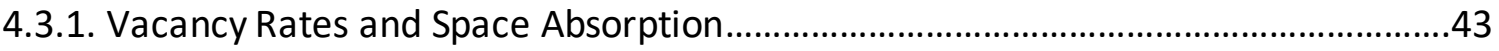

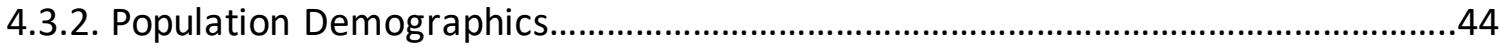

4.3.3. Income and Employment Demographics...............................................................46

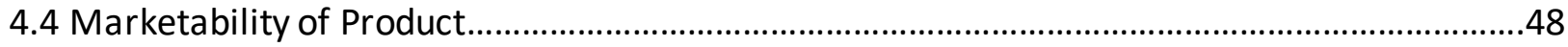

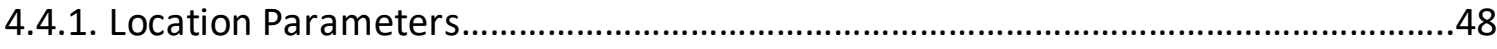

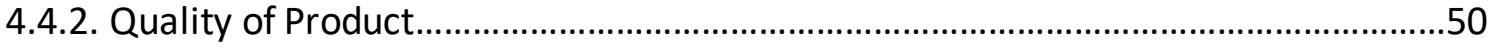

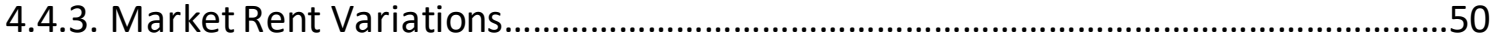

Chapter 5-Pro Forma and Analysis of Results

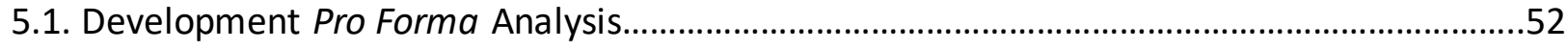




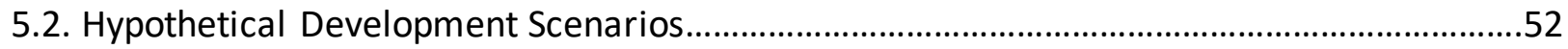

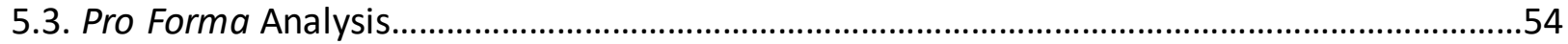

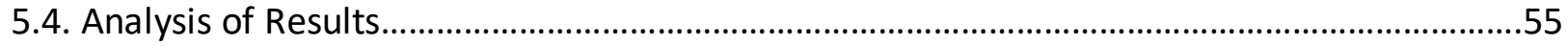

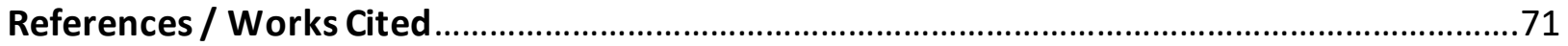

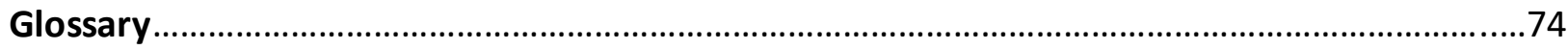




\section{List of Tables}

Table 1 - Environmental, Social and Economic Benefits Realized from Brownfield Remediation and Redevelopment...

Table 2 - Number of Ontario Municipalities Offering Various CIPs with Brownfield Provisions as of October, 2010.

Table 3 - Brownfield Incentive Policies offered in the Three Main Cities and Townships within the Region of Waterloo, Ontario.

Table 4 - Apartment Housing Estimates in Ontario.

Table 5 - Proportional Percentages of Dwelling Types in the Region of Waterloo, Ontario and Canada.....

Table 6 - CBRE Rental Unit Market Statistics across Canada.

Table 7 - NPV and IRR: Brownfield Redevelopment and Greenfield Development without CIPs.

Table 8 - NPV and IRR: Brownfield Redevelopment with Waterloo Approved CIPs. .59

Table 9 - NPV and IRR: Brownfield Redevelopment with Ontario Approved CIPs.......................60

Table 10 - NPV and IRR: Brownfield Redevelopment and CIP Mix Packages. .62 


\section{List of Figures}

Figure 1 - Geographical Representation of Ontario Municipalities with Brownfield Incentive

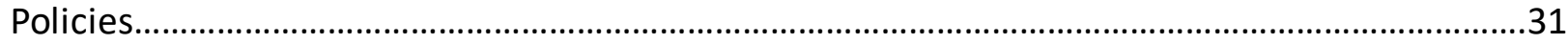

Figure 2 - Types of Purchasers for Canadian Real Estate Transactions above 10 million............40

Figure 3 - Pension Fund Allocations to Real Estate, 2015.........................................................41

Figure 4 -Investment Volume Comparisons, Region of Waterloo...............................................42

Figure 5 - National Trends in Multifamily Vacancy Rates...........................................................43

Figure 6 - Population Projections, Region of Waterloo............................................................45

Figure 7 - Population Demographics, Region of Waterloo.........................................................45

Figure 8 - Unemployment and Employment Statistics, Region of Waterloo...............................47 


\section{List of Appendices}

Appendix 1 - Brownfield Pro Forma: No Incentives....................................................................68

Appendix 2 -Sources and Uses of Funds: No Incentives.........................................................68

Appendix 3 - Brownfield IRR and NPV: No Incentives.............................................................68

Appendix 4 - Brownfield Project Returns: No Incentives..........................................................69

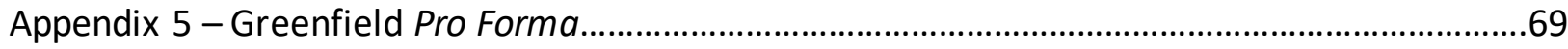

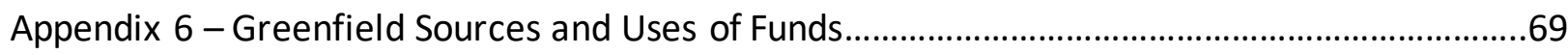

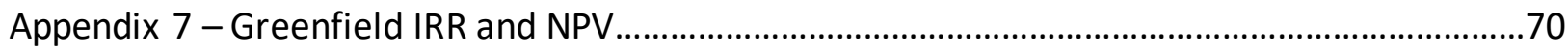

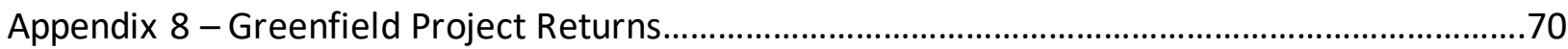

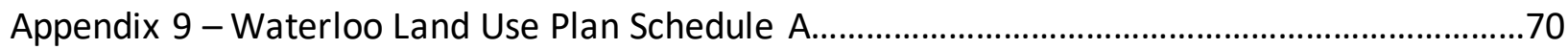




\section{Chapter 1: Introduction}

\subsection{The Problem: General Overview}

The brownfield redevelopment problem is an extensive issue being witnessed across North America and virtually in every other industrialized nation. Since the beginning of the $20^{\text {th }}$ century, industrialization has played a crucial role in helping to establish more productive economies. According to the Canadian Encyclopedia of Historic Canada, industrialization is defined as "a process of economic and social change which shifts the centres of economic activity on the focus of work, wages and incomes" (Marr, 2006). In Canada, economic and social activities which originally revolved around agricultural production were transformed to the manufacturing and production of goods and services (Marr, 2006). The commercial and industrial infrastructure needed to support and compliment the changing economy also required a shift from rural to urban settings, mainly urban city cores (Marr, 2006). Over time, industries gradually reversed this trend and shifted their operations from the city core to the surrounding suburbs which were desirable for development as much of the land was undeveloped greenfields (De Sousa, 2002). This urban development pattern from urban to suburban areas left a vast number of vacant urban industrial sites which had been contaminated and in many cases remain undeveloped leaving a tainted impression of a depressed economy and unhealthy polluted environments.

Brownfields, according to the Ministry of Municipal Housing and Affairs (MMAH) (2007) are "lands that are potentially contaminated due to historical, industrial or commercial land use practices, and are underutilized, derelict or vacant" (p.7). Thus in contrast, greenfields can be referred to lands which have not been subjected to any previous developmental pressure or infrastructure. The brownfield definition includes known contaminated sites as well as suspected sites based on their historical land-uses (De Sousa, 2002). In Canada and the U.S, the term brownfield is interchangeable with contaminated lands, derelict lands and former industrial sites; however, brownfields is more 
commonly used because it avoids the negative connotation associated with the word contamination as well as provides us with a semantic counterpart to greenfields (De Sousa, 2002).

Traditionally, there has been minimal interest on behalf of developers, land owners as well as private sector stakeholders in the redevelopment of brownfields. The fears of real or perceived contamination on these sites have made these redevelopment projects too expensive and risky to develop profitably (De Sousa, 2000). Furthermore, developers could be held responsible and liable for any future contamination impacts or adverse effects from brownfield redevelopment, thereby adding to the stigma or negative connotation associated with brownfield redevelopment (De Sousa, 2000). Unfortunately, Ontario does not currently have a permanent funding programme to help aid developers and private investors in redeveloping or rehabilitating brownfield sites, nor did it have any formal incentive mechanisms to attract private investment, until recently.

The development of greenfield sites in surrounding suburban peripheries is still the predominant trend in Canada thus making the brownfield problem very extensive as it is experienced in both urban and suburban communities (De Sousa, 2000). Unfortunately, only sporadic data can be found on the scale of the brownfield problem in Canada, and according to some estimates, as much as $25 \%$ of the urban landscape in Canada can be potentially contaminated as a result of the previous industrial activities (De Sousa, 2000). This problem is even more evident for (the residents of) Ontario; the Environmental Careers Organization Canada (ECO) in 2007 estimated that $40 \%$ of brownfields across Canada are found in Ontario (MMAH, 2007). Understanding the true scope of the brownfield problem is extremely difficult because Ontario does not have a brownfield inventory (for private and provincially owned brownfields) to identify the locations and magnitude of potential contaminated sites (De Sousa, 2000). 


\subsection{What is the Significance of Brownfields? Why is Brownfield Remediation Important?}

As the Canadian population continues to grow, the need for more infrastructures is becoming increasingly evident. Finding a place for this new infrastructure can be done in two ways: rebuilding on land that has already been previously developed, or building on undeveloped greenfields. As a form of sustainable development, brownfield remediation and redevelopment focuses on using already occupied resources and reduces the development pressure on greenfields and untapped resources (MMAH, 2007). Redeveloping brownfields not only serves to help preserve fixed environmental resources but also entails a greater number of benefits which can be realized in our economy, our environment and our overall health.

The key to redeveloping brownfields lies in their value. They have monetary value, cultural heritage value and social value. Environmental, social and economic benefits can all be realized from brownfield remediation; such benefits are listed in Table 1. The benefits of brownfield redevelopment do outweigh the costs. Leaving lands in an idle or underutilized state, with the potential of remaining contaminated, can present liability risks, financial losses and even potential adverse impacts to human health and the environment (MMAH, 2007).

Table 1 - Environmental, Social and Economic Benefits Realized from Brownfield Remediation and Redevelopment

\begin{tabular}{|l|l|l|}
\hline Environmental Benefits & Social Benefits & Economic Benefits \\
\hline $\begin{array}{l}\text { Reduction of development } \\
\text { pressure on greenfield sites }\end{array}$ & Renewal of urban cores & $\begin{array}{l}\text { Attraction of domestic and } \\
\text { foreign investment }\end{array}$ \\
\hline $\begin{array}{l}\text { Protection of public health and } \\
\text { safety }\end{array}$ & $\begin{array}{l}\text { Elimination of the negative social } \\
\text { stigmas associated with the } \\
\text { affected communities by } \\
\text { revitalizing them }\end{array}$ & $\begin{array}{l}\text { Restoration of the tax base of } \\
\text { government }\end{array}$ \\
\hline $\begin{array}{l}\text { Protection of groundwater and } \\
\text { soil resources }\end{array}$ & $\begin{array}{l}\text { Reduction of the fear of ill } \\
\text { health, environmental } \\
\text { deterioration and shrinking } \\
\text { property values in these } \\
\text { communities }\end{array}$ & $\begin{array}{l}\text { Increased utilization of existing } \\
\text { municipal services }\end{array}$ \\
\hline
\end{tabular}

Source: (DeSousa, 2000) 
Brownfield redevelopment serves as a form of sustainable development by not only reducing the development pressures on greenfield sites in suburban areas, but also provides an opportunity for developers to incorporate energy efficient technologies, building materials, water and waste management measures into their development projects (MMAH, 2007). Redeveloping a brownfield property can also increase a developers' score in the LEED ${ }^{\circledR}$ (Leadership in Energy and Environmental Design) rating system, which assigns points for "sustainable site" projects (MMAH, 2007).

Advocates for sustainable development and "smart growth" initiatives highlight the potential benefits associated with brownfield redevelopment as it encourages "smart" urban development (De Sousa, 2002). Brownfield redevelopment can help reduce the use of public funds for new infrastructure, help ameliorate the quality of the environment and can help improve the social conditions within local communities (De Sousa, 2002). The National Round Table on the Environment and the Economy's (NRTEE) brownfield strategy in 2003, estimate that every hectare of brownfields redeveloped saves 4.5 hectares of greenfield land (MMAH, 2007). They also estimate that for every dollar invested in brownfield redevelopment, $\$ 3.80$ gets invested into the economy (MMAH, 2007). It is quite evident that brownfield remediation not only helps protect human health and the environment, but can also improve economic conditions as well as help with future sustainable developments.

\section{3. (Roadblocks and) Deterrents to Brownfield Redevelopment}

There are many notable barriers on the path to brownfield redevelopment, and many of these roadblocks affect the different stakeholders in different capacities. Understanding the key stakeholders involved in brownfield remediation and the obstacles each stakeholder encounters will assist our understanding of the totality of deterrents to brownfield remediation for each of the key players involved. Generally, brownfield remediation involves many stakeholders: developers, private landowners, realtors, secured creditors and financial institutions, receivers, trustees in bankruptcy, 
foreign investors, and governments at all levels as well as the community. All of these stakeholders can be involved in brownfield remediation projects. Many of the obstacles encountered with brownfield remediation will impact the different stakeholders to different degrees and understanding this relationship will aid efforts to (help) accelerate brownfield remediation.

The main deterrents or risks posed by brownfield remediation and redevelopment, on the part of the private sector, revolve around three main obstacles: liability, costs, and government aid. Brownfield redevelopment is feared to be too costly, time consuming and financially risky as a profitable redevelopment or investment option as seen through the lens of the private sector (De Sousa, 2000). Adding the fear of future liability from adverse effects arising after (subsequent to) development leads to a further perceived increase in the riskiness of redeveloping a brownfield compared to a greenfield development (De Sousa, 2000). Previous research on U.S case studies illustrates that brownfield redevelopment is further hampered by the additional direct cost of remediation and consultation coupled with the prospect of low rentals or sale revenues (De Sousa, 2000). Furthermore, limited government funding and assistance to the private sector for brownfield redevelopment only decreases the viability and profitability which could arise from brownfield redevelopment. Interview responses from those involved in all aspects of brownfield redevelopment, showed that liability and high remediation costs were ranked as the two largest obstacles to brownfield redevelopment (De Sousa, 2000). Moderately-rated obstacles from the same interviews included deterrents such as policy, financing and property perception factors (De Sousa, 2000). De Sousa's (2015) most recent research highlights the same prevailing barriers to redevelopment and divides them into two categories; noninstitutional and institutional barriers (De Sousa, 2015). Interview responses confirmed that the most notable non-institutional barriers to redevelop remains that of cost, liability, time and the lack of available funding (De Sousa, 2015). Institutional barriers can be sourced from both the provincial and municipal levels of government and are related to matters such as the complexity of site specific risk 
assessments and the long duration of regulatory processes (De Sousa, 2015). Investigating and identifying all the risks and barriers involved in brownfield redevelopment is crucial for developers especially when trying to determine potential profits and project viability (MMAH, 2007). De Sousa's (2000) "Brownfield Redevelopment versus Greenfield Development: A Private Sector Perspective on the Costs and Risks Associated with Brownfield Redevelopment in the Greater Toronto Area" was one of the initial investigations of this issue and this study follows part of his methods to investigate the costs of brownfield redevelopment using current municipal incentive tools which can be offered to developers in Ontario.

\subsubsection{Liability}

Liability has been listed in many research papers as the largest deterrent to brownfield remediation, mostly by developers and private landowners. Environmental liability for any past, present or future contamination has been noted as the largest and most influential obstacle when it comes to brownfield redevelopment (De Sousa, 2000). When a developer seeks to purchase land from a private landowner for redevelopment, the developer or landowner could be held responsible for financing the entire remediation or clean-up, regardless of who was originally responsible for contamination in the first place. Developers can also be held liable for any adverse effects that could arise subsequent to development (MMAH, 2007). As a result of this highly-noted deterrent, in 2001 and 2007, the Ontario government passed legislation to protect the broad range of stakeholders and individuals involved in the remediation process known as limited liability (MMAH, 2007). In order to receive the limited liability protection, a Records of Site Condition (RSC) document must be filed in accordance with Ontario Regulation, 153/04. Once submitted and approved, limited protection can be granted from Ministry of Environment (MOE) environmental orders for the clean-up of historic contaminants remaining on the site (MMAH, 2007). However, this protection of liability does not extend to any contamination that may 
be discharged from the site and affects adjacent properties (MMAH, 2007). If the municipality takes control of a brownfield site, either through a failed tax sale or foreclosure, it too is also protected from MOE environmental orders on historic contaminants over a 5 year period from the time they take ownership of the site (MMAH, 2007). Understanding and managing the financial and environmental risks involved in brownfield remediation and redevelopment thus remains a key factor to the success and viability of a brownfield redevelopment. The impact of this financial liability will be strongly dependent on the type and magnitude of contamination as well as the method of remediation employed (MMAH, 2007). The potential risk from liability will impact each stakeholder differently and needs to be crossreferenced with that individual stakeholders' tolerance for risk to ultimately determine whether redevelopment occurs.

\subsubsection{Cost and Time}

Redeveloping a contaminated site can obviously be considered more costly than developing the same project on a non-contaminated greenfield. The presence of contamination leads to increased costs in removing the contaminated medium (soil or groundwater), remediating the site to regulated standards and then requires monitoring or maintenance to maintain the site at specified conditions.

Direct costs of remediation and site condition assessments are not incurred by greenfield developments which have ultimately made them a more desirable investment and development option. All development and redevelopment projects are mainly financially supported by loans (debt), with limited equity investments by the developer. As such, the time required to complete the project could impact the total costs of the project; having to remediate the site and gain the necessary permits or approvals from municipalities and the MOE can be a lengthy process which expands the timeline for project completion. Expanding the timeline for which the money is loaned increases the total amount of interest being paid on that loan. It is understandable that developers and private investors traditionally 
focus on greenfield developments at the edge of urbanized areas as they are seen to be less expensive and easier to develop (MMAH, 2007). Cost and time considerations are crucial factors directly impacting the rate at which brownfields become redeveloped. The potential profits from the project must outweigh the total costs and perceived risks to attract project proponents to carry out redevelopment (MMAH, 2007). To further complicate the costs of redevelopment, financial institutions or lenders are hesitant to finance brownfield projects because of the perceived risks they entail and, together with the lack of financial government assistance and the difficulties in obtaining insurance, the reluctance to provide financing is that much more difficult to overcome (De Sousa, 2000). De Sousa's (2000) study further revealed most interviewees felt that financial mechanisms such as tax incentives, funding subsidies and guaranteed loans would significantly reduce the costs of remediation as well as diminish the associated risks which should eventually lead to accelerated brownfield redevelopment.

\subsubsection{Lack of Government Incentives and Fragmented Regulatory Policy}

Management of the environment in Canada is a shared responsibility among the three levels of government. The federal, provincial and municipal governments each take on different parts of this responsibility (De Sousa, 2006). The federal government is only responsible for federal brownfield sites. Most of the regulations for brownfield redevelopment are primarily the responsibility of the provincial and municipal levels of government. The general approach of the government at these levels has been to hold the private sector primarily responsible for clean-up and redevelopment while the government plays a regulatory and advisory role. The specific municipal responsibilities for brownfield redevelopment can be multifaceted and will vary depending on what is permitted by the provincial legislation as well as site ownership.

Both the federal and provincial governments have created advisory councils and agencies (Canadian Council of Ministers of the Environment (CCME), MMAH and NRTEE (now disbanded)) to help 
identify the main roadblocks to brownfield redevelopment as well as to create non-enforceable guidelines for clean-up protocols; however, the lack of clarity and uncertainty created by different environmental laws across the country for environmental liability and clean-up responsibility further complicates and hinders the process of brownfield remediation and redevelopment (De Sousa, 2000).

These clearly are issues or deterrents to brownfield redevelopment and can be validated by the interview responses in De Sousa's $(2000,2015)$ research and also touched upon in the reports generated by the NRTEE and CCME on brownfield remediation. Unfortunately, little political and economic support comes from the upper levels of government (federal and provincial) and thus most of the burden for stimulating and managing brownfield redevelopment remains the responsibility of the municipality (De Sousa, 2002). Half of the interviews conducted by De Sousa's (2000) research paper identified tax incentives (tax abatement, tax increment financing and development charge credits) as specific initiatives that the provincial and municipal governments could take that would (benefit or) remove economic obstacles associated with brownfield redevelopment (De Sousa, 2000). Half of the De Sousa's (2000) interviews also illustrated that protection from future liability from the government would be one of the most useful mechanisms for attracting more brownfield redevelopment (De Sousa, 2000). There is also very little technical, regulatory or development assistance available for developers and private landowners for the remediation of potentially contaminated lands. Providing more assistance in these areas would help to reduce the general frustration associated with brownfield redevelopment (De Sousa, 2002b).

In Europe and the U.S, responsible governments have employed a variety of economic and environmental policies to lessen the associated costs and risks for brownfield redevelopment (De Sousa, 2000). Unfortunately, at the time of the study, Canada had been moving much slower than other countries in terms of implementing the appropriate policies and programmes necessary to help private 
sector development. The Canadian government had a policy position that the brownfield problem could be solved solely by the private sector without government interference (De Sousa, 2000). De Sousa's (2000) study of development costs and risks illustrated (a gap in the relevant literature on) the limited effectiveness of then existing brownfield policies and programmes by substituting American and European policies into the context associated with Canadian brownfields.

\subsection{Research Objectives}

This research paper aims to investigate Ontario's CIP brownfield incentives and how they quantitatively aid investor returns, a tactic which could not be employed in the De Sousa's (2000) research paper. Of all CIPs with brownfield provisions offered in Ontario, regional development charge (RDC) exemptions should produce the greatest impacts on an investor's return followed by the tax increment equivalent grants (TIEG). Regional development charges will produce the largest impact on investor returns because they comprise the largest amount of subsidies being offered. However, the amount of funding given in the RDC is dependent on the municipality and Minister of Finance and thus in certain circumstances (where a fully funded RDC is not available), RDC exemptions may not be as influential in providing a greater cushion for the costs of development as a TIEG would provide.

Understanding the quantitative relationship on the financial incentives being offered to developers for brownfield redevelopment will provide policy makers with a sensitivity analysis of the different incentives offered such that they can redirect their policy initiatives to focus on the most powerful CIP incentive tools. Policy efforts and CIP packages can then be tailored to provide a larger form of relief on the costs of brownfield redevelopment which instinctively will help reduce development pressures on greenfields and promote a more sustainable form of residential development. 


\section{Chapter 2 - Literature Review}

\section{$\underline{2.1 \text { - Government Policy and Guidelines Literature }}$}

This section discusses the existing literature on government policy and guidelines for contaminated sites.

\subsection{1 - Establishing National Guidelines and Programs for Contaminated Sites}

The federal government's affiliated agency, originally known as the Canadian Council of Resources and Environment Ministers (CCREM), (renamed the Canadian Council of Ministers of the Environment, CCME) started producing the earliest national guidelines in Canada for site remediation starting with interim guidelines for the contaminant of Polychlorinated Biphenyls, otherwise commonly known as PCBs in 1987 (Sheppard et al., 1992). The guidelines were based on the impacts of human exposure to the PCB contaminants via ingestion of soil and the affiliated contaminated meat and dairy products (Sheppard et al., 1992). In 1989, recognizing the necessity to take action and remediate contaminated sites, the CCME and Government of Canada (GOC) negotiated a joint \$250 million, fiveyear "National Contaminated Sites Remediation Program" (NCSRP) for all the provinces and territories (Government of Canada, 2015). This program was responsible for remediating federal orphaned contamination sites of high risk while also promoting Canada's environmental technology industry and involved 45 federal contaminated sites and the initiation of 55 site remediation technology projects (Government of Canada, 2015). Through this program, the national government established its first attempts for classifying contaminated sites according to their current or potential adverse impacts to human health and the environment (Government of Canada, 2015).

The establishment of the "National Contaminated Sites Remediation Program" also recognized the need to establish both generic and site-specific advisory guidelines for contaminated sites. The 
CCME set up two subcommittees, the Subcommittee on the Classification of Contaminated Sites and the Subcommittee on Environmental Quality Criteria for Contaminated Sites, which were responsible for creating reports to enable classifying contaminated sites and the management of these sits, as well as developing both generic and site specific guidelines for site remediation (CCME, 1996a, 1996b, 1997)

In 1992, the "National Classification System for Contaminated Sites" (NCSCS) report was released to provide a simple, consistent and reliable tool to aid in the evaluation of classifying sites in terms of the current or potential risks they pose to human health and the environment (CCME, 2008). This five step system was not only instrumental in establishing a convenient basis for assessing sitespecific contamination on a ranking basis, but also for determining whether individual sites qualified for NCSRP funding (CCME, 2008). The NCSCS helped established a rational and scientifically defensible system for comparing and classifying contaminated sites in Canada (CCME, 2008). From its inception in 1992, the NCSCS was originally developed based on existing provincial, territorial and international methods for classifying contaminated sites (CCME, 2008). However, in its most recent and updated version in 2008, new information and new knowledge has contributed to help update the risk assessment techniques and thus the suitability of this system for classifying contaminated sites across Canada.

In 1996, the CCME released its “Guidance Manual for Developing Site-specific Soil Quality Remediation Objectives for Contaminated Sites in Canada" as another part of the National Contaminated Sites Remediation Program (NCSRP) (CCME, 1996a). The purpose of the report was to provide a national framework for site-specific guidance of assessing and remediating contaminated sites in Canada (CCME, 1996a). In addition to these documents, the CCME and GOC also released other documents to assist site managers in the assessment and remediation process. The "National Guidelines for Decommissioning Industrial Sites" (CCME, 1991) and the "Guidance Manual on Sampling, Analyses, 
and Data Management for Contaminated Sites Vol I. Main Report, Vol II Analytical Method Summaries" (CCME, 1993) are just two of the many documents created as a part of the NCSRP program (CCME, 1996).

Unfortunately, critical evaluations of the federal programs and their inadequacies surfaced in a 2002 "Report of the Commissioner of the Environment and Sustainable Development" which highlighted its failure to produce an action plan dealing with high risk sites in a timely manner as well as providing long-term funding for managing the problem (Government of Canada, 2015). As a result, in 2003 the Government of Canada announced funding of $\$ 175$ million to accelerate the remediation of high risk sites over a 2 year period, and in 2004 the federal budget committed $\$ 3.5$ billion for the "Federal Contaminated Sites Action Plan" program which was initiated in 2005 (Government of Canada, 2015)). Current reports taken from the executive summary of the "Federal Contaminated Sites Action Plan" now list the program as a 15 -year, $\$ 4.2$ billion program (CCME, 2008). The primary objective of the program is to reduce the current and potential risk to human health and the environment from contaminated sites as well as reduce the related financial liabilities from federal sites (CCME, 2008).

\subsection{2 - Establishing Provincial Guidelines and Programs for Contaminated Sites}

Recognition of soil contamination and the need to develop soil quality guidelines to protect human health and the environment in Canada were initiated by the Province of Ontario. The Ontario Ministry of the Environment (MOE) created its first soil quality guidelines in 1984 (Sheppard et al., 1992). For each substance or contaminant identified, up to four values were recommended in the soil quality guidelines which would be applied to two broad categories of land use and two categories of soil texture (Sheppard et al., 1992). During the 1980s and 1990s, Canadian provinces started to witness the first escalation of the development of generic guidelines for contaminated sites. By 1989, the Ontario Ministry of the Environment issued its final version of its "Site Decommissioning Guidelines" and the 
British Columbia Ministry of the Environment released its draft for remediation guidelines for soil and groundwater (Sheppard et al., 1992). The "Site Decommissioning Guidelines" report detailed a process for meeting MOE requirements when cleaning up contaminated sites and helped outline the managerial and technical procedures required in this regard (CCME, 1991). These guidelines could then be applied to all provincial, municipal and privately owned sites and facilities where environmental contamination has been found (Sheppard et al., 1992).

In 1991, Ontario initiated the Advisory Committee on Environmental Standards (ACES), which would be responsible for creating a program allowing the provincial government to solicit inputs on each contaminant they have historically dealt with, and thus allow for many disciplines and different regions to contribute their data and opinions (Sheppard et al., 1992).

\subsubsection{Brownfield Regulation in Ontario}

Regulation of brownfields falls primarily to the provincial and municipal levels of government. While the federal government plays a more managerial and advisory role, provincial and municipal levels of government are responsible for regulating brownfield redevelopment within their jurisdiction as well as providing the necessary financial incentives and liability protections for brownfield redevelopment.

The Environmental Protection Act, 1999 is described as an act providing the "protection and conservation of the natural environment" (Ontario Government, 2016). The EPA came into force in 2000 and since then has included many amendments to help protect human health and preserve environmental integrity. The most notable amendment to the act in relation to brownfield policy and regulation can be found in the Brownfields Statute Law Amendment Act, 2001 (Ontario Government, 2001). 
Through the Brownfields Statute Law Amendment Act, 2001, legislative and regulatory amendments have been made in efforts to encourage the revitalization of underutilized potentially contaminated lands (Ministry of Environment, 2004). The brownfield amendments made in through this act do not influence other sections of the Environmental Protection Act (Ministry of Environment, 2004).

The "Records of Site Condition: A Guide on Site Assessment, the Cleanup of Brownfield Sites and the Filing of Records of Site condition", 2004 describes the legislative and regulatory requirements for assessing the environmental condition of the site, the cleanup of brownfields as well as the filing of RSC documents on Ontario's Environmental Site Registry. The guide provides property owners, consultants, municipalities and other stakeholders with an overview of the requirements for brownfield remediation and redevelopment under parts XV.1 and XV.2 of the Environmental Protection Act (EPA) and the regulations falling under those acts (Ministry of Environment, 2004). The guide focuses on the requirements for site assessment and cleanup as well as the filing of an RSC document as required under parts XV.1 and XV.2 of the EPA (Ministry of Environment, 2004). The guide also explains the provisions which have been made to Ontario Regulation 153/04 (Records of Site Condition) concerning protection from liability and cleanup orders from the MOE under part XV.1 applying to property owners, and part XV.2 which applies to municipalities, secured creditors and others requiring certain investigative actions related to brownfield sites (Ministry of Environment, 2004). In order to submit an RSC document, an Environmental Site Assessment (ESA) must be carried out and part of the RSC document. ESA can be divided into a Phase 1 ESA and Phase 2 ESA. As stated by the MOE (2004), Phase 1 ESA determines the likelihood that one or more contaminants may be present and affecting the property, and under Ontario Regulation 153/04, must include: "a records review, a site visit, interviews, an evaluation of the information from these activities, the preparation of a written report and submission of the report to the client (property owner)" (pg. 7). A Phase 2 ESA includes sampling and analysis of the property if 
deemed necessary in the Phase 1 report. Specific requirements for submitting a Phase 2 ESA are listed in Part VIII of Ontario Regulation 153/04 (Ministry of Environment, 2004).

\subsection{Brownfield Remediation - Sustainable Growth Measures}

This section examines the sustainable growth measures from brownfield redevelopment as it pertains to the growth management and planning policy documents for both Ontario and the Region of Waterloo, Ontario.

\subsubsection{Brownfield remediation - Sustainable Growth Ontario}

The Provincial Policy Statement (PPS) of 2014 is a complimentary policy document to the Planning Act providing policy direction to decision makers on land use planning and development such that Ontario's long-term environmental health and social well-being are preserved (MMAH, 2014). This can be done though promoting healthy, liveable and safe communities which can be sustained by (MMAH, 2014):

- Promoting efficient development and land use patterns;

- Avoiding development and land use patterns which may cause environmental or public health and safety concerns and hinder the ability for of efficient expansion of settlement areas; and

- Sufficient land should be made available through the intensification and redevelopment in designated growth areas to accommodate an appropriate range and mix of employment, housing and other land uses.

The intensification and redevelopment section of the Provincial Policy Statement by the MMAH (2014) highlights that accommodating already developed and redeveloping existing sites, including brownfields, shall be considered and intensification and redevelopment will be directed in accordance 
with goals set out in sections 2 and 3 of the PPS document. The policy statement also addresses that long term economic prosperity would be supported through the promotion of brownfield redevelopment.

\subsubsection{Local Policy for Brownfield Redevelopment - Sustainable Growth Waterloo}

Regional growth management strategies in Waterloo's Regional Official Plan coincide with the "Places to Grow: Growth Plan for the Greater Golden Horseshoe" with respect to creating a sustainable and liveable Waterloo Region by planning for healthy and prosperous growth throughout Ontario (City of Waterloo, 2014). Economic growth from a sustainability perspective also entails protection of the environment by maintaining, enhancing and restoring the natural environment (City of Waterloo, 2014). Redeveloping contaminated lands does enhance the environmental conditions and, as well, it reduces the development pressures on natural greenfield landscapes. With an increasing population and the associated increased need for more supporting infrastructure, the City of Waterloo is one of Ontario's fastest growing areas and it has become clear that the need for growth management, which includes brownfield redevelopment, is crucially important to maintaining a liveable area.

A part of the "Regional Growth Management Plan" for the Region of Waterloo includes the "Waterloo Reurbanization Community Improvement Plan" which emphasizes its goal of reurbanization within the City of Waterloo. Reurbanization involves directing residential and non-residential development within the already built-up areas to slow down the rate of expansion into suburban greenfield peripheries (City of Waterloo, 2014). The primary focus area for this reurbanization is the Central Transit Corridor (CTC), an area which connects three urban communities of Cambridge, Kitchener and Waterloo and is a location of increased transit infrastructure and the necessary residential developments needed to compliment the growing population (City of Waterloo, 2014). Market conditions and population characteristics, combined with future infrastructure developments, could 
replicate the trends witnessed in Toronto during the late 1990s which emphasized residential brownfield redevelopment. If the Region of Waterloo and its municipalities have approved community improvement plans (CIPs), under section 28 of the Planning Act, the municipality can also pass more bylaws under the "Regional Reurbanization Facilitation Program" (RRFP) to acquire and prepare lands for development which can include brownfield redevelopment (City of Waterloo, 2014).

\subsection{Brownfield Remediation Studies - Scientific Literature}

In its earliest stages, establishing remediation guidelines for dealing with contaminated sites was difficult due to the scarcity of related scientific and technological literature on soil contamination and its impacts to human health and the environment. It has been observed that the sources for contamination can be quite diverse ranging from coal tar pits, scrap yards, mine tailing wastes, leaking of underground storage tanks, deteriorating hazardous waste storage facilities and more (Sheppard et al., 1992). Furthermore, the wide array of contaminants which can be present (such as heavy metals, toxic elements, volatile and non-volatile organics, radioactive isotopes) as well as the inherent variation in terms of their behaviors and impacts troubled biologists, chemists and even ecotoxicologists early on (Sheppard et al., 1992).

Much of the scientific literature in the scientific community on traditional soil science focused on aspects of soil structure, organic matter content and nutrient levels; however, the urgency of dealing with contaminated lands switched the focus to expand our understanding of soil quality, contamination and its impacts on humans and the environment (Sheppard et al., 1992). This fundamental shift led scientists to look at the dynamic multifunctional ecological components of soil which were critical for sustaining environmental integrity and protecting human health (Sheppard et al., 1992). Scientists began looking to establish links between contamination, the hazards present and the pathways from which this exposure could occur (Sheppard et al., 1992). 
The first provincial soil quality guidelines in Canada were developed in 1984 by the Ontario Ministry of the Environment. Their guidelines were substantially different from those seen in other nations. Differentiating ourselves from the UK and Netherlands, up to four values were recommended for each substance or contaminant present, which could then be applied to two broad categories of land use and two different categories for soil texture (Sheppard et al., 1992). These values were not only based on professional judgement, but also considered ambient background levels, the health of grazing animals living off the land, phytotoxicity and human health (Sheppard et al., 1992). In Quebec, the “Minstere de I'Environnement du Quebec (MENVIQ) drafted its own soil quality guidelines in 1986, which were modelled the "ABC" approach in the Netherlands in 1983 (Sheppard et al., 1992).

The first Canadian federal guidelines established for contaminated sites were created in 1987, by the Canadian Council of Resource and Environment Ministers (CCREM) which was renamed later as the Canadian Council of Ministers on the Environment (CCME). As mentioned in section 2.1.1. the first report released by this agency was in the form of interim guidelines for polychlorinated biphenyls, also commonly known as PCBs (Sheppard et al., 1992). These interim guidelines were created based on the potential risks of human exposure through ingestion of soil or the contaminated meat and dairy products associated with the contaminated soils. These PCB guidelines were quickly followed by more interim guidelines for nine organic compounds found at abandoned coal tar sites by the CCME in 1989 (Sheppard et al., 1992). Comprehensive soil quality guidelines were established for many other contaminants through the 1989 "National Contaminated Sites Remediation Program" (Sheppard et al., 1992). According to Sheppard et al., (1992), it was documented that the guidelines were defined as "numerical limits or narrative statements intended as general guidance for the protection, maintenance, and improvement of specific uses of soil" (pg.365). These numerical limits or values were derived from scientific data about the observed impacts that contaminants had on human health and the environment incorporated with critical evaluations of existing guidelines in other jurisdictions (Sheppard 
et al., 1992). However, it is important to note that this derivation did not include technical limitations, socio-economic effects or management and political factors which were considered site-management issues (Sheppard et al., 1992).

Unfortunately, the generic guidelines created by the CCME did lead to controversy over its lack of supporting scientific rationale and did not address the issues which were deemed most important in the scientific and political communities (Sheppard et al., 1992). These inadequacies were well documented. As a result, generic guidelines were viewed as an important common basis for site contamination remediation helping to streamline the initial screening phases of assessment; however, they could not solely be used as remediation guidelines but rather more as (an) interim measures coupled with more site-specific guidelines before regulatory requirements or remedial actions can be confirmed (Sheppard et al., 1992). To cover the entire multiplicity of contaminated lands and the threats they pose to human health and the environment, requirements for pollution control and site remediation should be based on several criteria such as local conditions, existing guidelines and standards set out, available technologies for site remediation, socioeconomic conditions as well as future land use and possible downstream pathways for water discharge (Smith et al., 1995).

\subsection{Problems to Brownfield Remediation - Parent Study and Filling in the Gaps}

Identifying the gaps of supporting literature on the effectiveness of government incentives to battle the economic costs and risks from brownfield redevelopment stemmed from De Sousa's 2000 research paper. Through interviews, case studies and hypothetical development appraisals, De Sousa illustrated that negative perceptions or stigmas surrounding the cost and liability associated with brownfield redevelopment is experienced by the many stakeholders involved. However, incorporating incentives and policies seen in Europe and the United States to a brownfield situation in Ontario could be feasible and desirable given the assumptions of the study. A more intensive study involving current 
Ontario municipal incentives should be undertaken to determine the effectiveness of these incentives. By carrying out hypothetical development appraisals with current municipal incentives and policies, a quantitative cost analysis could be undertaken to look at the impacts on investor returns and ultimately determine how feasible brownfield redevelopment in Ontario currently is.

Traditionally, interest on the part of developers, landowners and other stakeholders potentially involved in brownfield redevelopment has been minimal due to the associated perceptions of perceived contamination and the high cost and liability associated with such projects (De Sousa, 2000). As a result, developers and private investors are often unwilling to get involved with brownfield remediation. To further complicate the issue, getting sites back to productive use from operations solely funded by the provincial and/or municipal government is unachievable. Governments cannot ensure the remediation of the plethora of brownfield sites without the assurance of private investment (De Sousa, 2000). Subsequently, policy and programmes in Canada to counteract greenfield development has moved much slower than in other countries largely because of an ingrained perception from policy makers that this situation can be solved by the private sector itself without government interference and support (De Sousa, 2000).

Interviews in De Sousa's (2000) research concluded that liability concerns and large remediation costs continue to rank as the largest obstacles to brownfield redevelopment followed by the lack of government incentives and the difficulties of obtaining financing. From the hypothetical pro forma created, for a residential site scenario, the study concluded that despite the high costs of residential brownfield redevelopment, brownfield redevelopment projects in (the urban study area of) Toronto were more profitable than their greenfield development counterparts in suburban areas, primarily because of the high land values experienced in the primary market of Toronto (De Sousa, 2000). 
Unfortunately, brownfield redevelopment is still perceived as a more costly and risky development option compared to greenfield developments, and greenfield development in suburban peripheries does remain to be the predominant trend in Canada (De Sousa, 2002 b). Even though the City of Toronto did experience a substantial increase in brownfield redevelopment through residential redevelopment, much of this was made feasible through high valued land and provided the ability to recover costs (De Sousa, 2002 b). However, Toronto is not the only market in Ontario where market conditions can permit financially feasible residential brownfield redevelopment. Other markets, such as the City of Waterloo, are experiencing rapid growth and could lead to a potentially advantageous scenario for both developers and municipalities in bringing brownfield sites back to productive use for secondary markets. In fact, from the (2002) report "Brownfield Redevelopment in Toronto: An Examination of Past Trends and Future Prospects", the Toronto case study highlighted three key implications to the success of other jurisdictions redeveloping brownfields in their urban core:

- Allow market forces to dictate the course and outcome of brownfield redevelopment;

- Local governments and other planning organizations are capable of more than just a managerial role to brownfield redevelopment; and

- The Toronto case reveals that residential brownfield redevelopment constitutes an excellent alternative to the industrial and/or commercial redevelopment of brownfields. 


\section{Chapter 3 - Incentive Packages}

This chapter describes the many financial incentives which can be offered to municipalities in Ontario through their CIPs.

\subsection{Municipal Financial Incentives}

Redeveloping brownfields is an environmentally positive form of development for all communities; not only does it encourage the intensification of redeveloping contaminated sites as well as sustainably using existing infrastructure, it also helps stimulate neighbourhood rejuvenation (MMAH, n.d.). Brownfield redevelopment also helps to improve air, soil and water quality by helping to heal the scars of our ecological footprints from past developmental activities. The aforementioned potential benefits can be experienced by redeveloping brownfields all across Ontario. According to De Sousa, (2015), "the redevelopment of brownfields is seen to offer a "triple benefit" in terms of remediating pollution, removing neighbourhood blight, and providing new development and employment" (pg.19).

The economic and social benefits stemming from brownfield redevelopment extend to all stakeholders, including governments and the community as a whole. As a result the Ontario government has made brownfield redevelopment a pivotal focus for sustainable growth management. To clearly articulate the role that brownfield redevelopment plays in sustainable development, the Ontario government has included brownfield redevelopment in certain provincial policies such as "The Greenbelt Plan" and the "Growth Plan for the Greater Golden Horseshoe" (MMAH, n.d.).

Unfortunately, brownfield redevelopment is associated with negative connotations such as the fear of real or perceived contamination and the high redevelopment costs associated with such site conditions. This not only adds to the time of project completion, but also complicates the project's financing options by creating additional concerns on behalf of lenders and financial institutions. Since the environmental condition of many brownfields is unknown, many investors are deterred from a 
development option in comparison to greenfields which are perceived to be less costly and time consuming (MMAH, n.d.). In order to offset these limitations, provinces have empowered municipalities to offer financial incentives to attract brownfield redevelopments to their jurisdictions (MMAH, n.d.). This research will discuss the different tools or options that communities can provide to the different stakeholders involved in brownfield redevelopment and will only focus on the financial tools with brownfield provisions. These incentives will then be used in our pro forma analysis to determine quantitatively how they impact investor returns on equity.

\subsection{Community Improvement Plans (CIP)}

Community Improvement Plans, otherwise referred to as CIPs, are a set of financial tools that municipalities can offer to help stimulate brownfield redevelopment. Under section 28 of the "Planning Act", all or part of a region within municipalities can be designated as a Community Improvement Project Area (CIPA) (MMAH, n.d.). Once a regional area is designated as a CIPA, the municipality can prepare a specific CIP which pertains to that region (MMAH, n.d.). Municipalities can thus offer tools providing financial assistance for certain community improvement activities taking place within that designated CIPA; this is a special exception to the rule against municipalities offering bonuses or other forms of financial incentives to businesses (MMAH, n.d.). Many Ontario municipalities have adopted CIPs which can be offered to a wide range of development and infrastructure; this research will strictly focus on the CIPs which are offered as they relate to brownfield redevelopment and contain brownfield provisions.

Research undertaken by the MMAH as of October 1, 2010 identified that 44 Ontario municipalities have adopted CIPs containing brownfield provisions (MMAH, n.d.). Of these 44 municipalities, 19 have a CIPA which is designated to cover the entire municipality and thus the CIPs can be applied to any brownfield located within that jurisdiction (MMAH, n.d.). For the remaining 25 
municipalities, CIPA areas were designated as specific areas based on any former industrial or commercial sites posing an environmental concern. The financial incentives offered in a CIP can be tailored to address the different and specific problems each area faces. Furthermore, given that approval from the Minister of the MMAH is no longer required for CIPs, there may be additional municipal CIPs containing brownfield provisions which are not identified and included in this report (MMAH, n.d.). Here we discuss the many available tools offered in CIPs, which can be used in conjunction (with one another) to create a "best mix package" or the best coupling of financial assistance measures to help generate the greatest returns for investors while also limiting cost and liability as much as possible.

\subsubsection{Study Grant Program}

Some municipalities may provide study grants which either reimburse all, or part of, the costs when undertaking various environmental remediation studies to access the environmental condition of the land (MMAH, n.d.). These environmental remediation studies take into account the true level of contamination at that particular site and the associated remediation costs necessary to remediate the site back to applicable standards. In order to receive these study grants, municipalities may dictate that certain requirements are met such as having an application for the remediation study to be submitted before actually commencing the study (MMAH, n.d.). The pay-outs for these grants will either be allocated once the remediation costs have been submitted and verified, or when the final study has been submitted and approved by the municipality itself (MMAH, n.d.). The value of these grant pay-outs can vary. Some municipalities can limit the number of grants, or the value of a grant provided per property (MMAH, n.d.). Here is a list of applicable studies which could be subjected for reimbursement:

- Feasibility Studies (structural or market analysis, concept plans, urban design studies),

- Phase 1 or Phase 2 ESA, 
- Remedial Work Plans or Risk Assessments (RA),

- Designated Substance and Hazardous Materials Surveys.

\subsubsection{Rehabilitation and Redevelopment Grants/Loans}

Up-front eligible rehabilitation and redevelopment activities can also receive financial assistance which is provided at the start and not after the costs have been accrued by the developer or private land owner (MMAH, n.d.). This type of financial incentive is not commonly offered by municipalities in Ontario because of the difficulties in understanding how to fund these grants at the outset and what to do if the project later goes into default (MMAH, n.d.). Some municipalities will designate this under their

CIP as a 'Rehabilitation and Redevelopment Grant' by name; however, this generally just refers to financial assistance through tax increment equivalent grants as opposed to grants provided at the start (MMAH, n.d.). Few examples do exists of municipalities offering these rehabilitation grants, but these are few and far between.

For example, in Hamilton a grant is only offered to target specific high priority areas within the region by providing a low-interest loan which can amount to $80 \%$ of remediation costs, with a maximum of $\$ 400,000$ per project (MMAH, n.d.). This loan is referred to as the "bridge" to help finance the rehabilitation costs and is only offered until developers can receive grant money offered through other city programs (MMAH, n.d.).

Another example is Sarnia's "Building Rehabilitation Loan Program". As identified in their CIP, it is a financial tool used to help stimulate interest in redeveloping any contaminated sites that can be put back into productive use (MMAH, n.d.). Grant funding is made available through a "revolving fund basis" which stipulates that the loan is offered at a below-prime interest rate and is to be paid back over a period of 10 years. The maximum value of the loan is $\$ 100,000$ or the total cost of the rehabilitation project, funding whichever value is less (MMAH, n.d.). 


\subsubsection{Tax Assistance Program}

The tax assistance program, in association with section 365.1 of the 2001 Municipal Act, as well as section 333 of the 2006 City of Toronto Act, summarizes the tax assistance program as a deferral or cancellation of the municipal and/or school portions of property tax (MMAH, n.d.). Municipalities must first offer the deferral or cancellation of the municipal portion of the tax for an eligible brownfield property before receiving provincial consideration for deferral of the school portion (MMAH, n.d.). To obtain this cancellation or deferral on the school portion of the tax, a municipality must apply to the Minister of Finance to provide matching education tax assistance (MMAH, n.d.).

Tax assistance can only be provided to eligible properties and can only assist with eligible costs of environmental remediation and rehabilitation (MMAH, n.d.). This tax assistance can also be provided throughout the remediation process or development phases of the project (MMAH, n.d.). This remediation timeline is defined as the period starting when the by-law is passed and extends over a period of eighteen months, or when the RSC is filed, or when the tax assistance is equal to the eligible remediation costs defined under section 168.4 of the Environmental Protection Act (MMAH, n.d.). A development period is defined as one that begins when the rehabilitation period ends, and concludes at an end-date that is specified by the by-law or when the tax assistance is equal to the total remediation costs (MMAH, n.d.). Municipal by-laws are required when cancelling or deferring part or the entirety of the municipal and/or school portions of the tax (MMAH, n.d.). In order for this assistance to be applied to the school portion, the relevant by-law must be approved before being submitted to the Minister of Finance (MMAH, n.d.). These municipal by-laws generally dictate a timeline from which they are applicable to tax cancellation for a specific property. To receive the educational tax assistance from the province, the allowable time period is stipulated in the BFTIP guideline which is established by the Minister of Finance. As of 2010, this is currently three years (MMAH, n.d.). Time periods for tax 
assistance negotiated between the municipality and the province can vary (MMAH, n.d.). Once approved, educational tax assistance is an entitlement to the property owner and concludes, as per program rules, when the title is transferred, when there is a severance or plan of subdivision (MMAH, n.d.). Municipalities, when deciding the municipal portion, can determine how their tax assistance is to be terminated, but this must be done in accordance with municipal and/or provincial legislation (MMAH, n.d.).

\subsubsection{Tax Increment Equivalent Grant (TIEG)}

A TIEG can be referred to as a form of financial assistance offered to offset either a portion or all of the municipal property tax increases which arise upon completion of the project and the appreciation of land values (MMAH, n.d.). Municipalities can predict or estimate the value of this financial assistance by using a "base assessed value" (MMAH, n.d.). Under section 28 of the Planning Act, municipalities can provide this type of grant or loan for a CIP in a designated CIPA; however, the use of a TIEG typically offsets eligible remediation and redevelopment costs (MMAH, n.d.). This form of financial assistance is offered over a maximum (time) period of 10 years, or until the total amount of eligible remediation and redevelopment costs has been offset (MMAH, n.d.). If municipalities offer both a tax assistance program and a TIEG, the TIEG generally commences when the tax assistance program has ended (MMAH, 2010). Section 28 of the Planning Act will outline the eligible costs of a CIP, but it is under the responsibility of the municipality to determine which of the specific costs are funded. Typical examples of specific costs that are funded within most municipalities include:

- Phase 2 ESA, Remedial Work Plans and Risk Assessments Costs (RA),

- Environmental Remediation Costs (cost in preparing a RSC document, tipping fees for contaminated soils, clean fills and grading),

- Environmental Insurance Premiums Related to the Above. 
TIEGs are generally referred to as the "pay as you go grants" because the owner is responsible for the up-front remediation and redevelopment costs and the owner must pay the land taxes in full each year. It is only after the development is completed, that the municipality will offer a grant which equates to the tax increment (MMAH, n.d.).

\subsubsection{Façade Grant or Loan Program}

The facade grant is generally offered to offset the costs associated with maintaining, rehabilitating and/or improving or restoring the buildings' exterior (MMAH, n.d.). This program is found in conjunction with a CIP in a designated CIPA and usually focuses on particular areas of a municipality, such as the central area or downtown core as opposed to city-wide CIPs (MMAH, n.d.). Some municipalities will even offer this type of grant to rehabilitation and remediation projects involving brownfields but they must still be located within the CIPA designation (MMAH, n.d.).

\subsubsection{Municipal Fees Grant Program}

Some municipalities can even offer grants that equate to all or a portion of the various municipal fees related to development (MMAH, n.d.). These fees widely vary among municipalities, but can include and are not limited to:

- Planning and Development Application and Permit Fees (minor variances, site plan approvals),

- Building Permit or Demolition Permit Fees,

- Sign Permit Fees,

- $\quad$ Land Tipping Fees.

In many municipalities, these fees are also paid out at the outset by the developer and/or land owner, who is later reimbursed by the municipality for these eligible fees in the form of a grant (MMAH, n.d.). 


\subsubsection{Development Charge Reductions or Exemptions and Equivalent Offsets}

Another financial assistance tool used by municipalities to promote brownfield redevelopment is aimed at exempting all or part of the development charges for applicable properties (MMAH, n.d.). Such reductions or exemptions are generally provided by a municipality through its development charges payable as specified in the development charges by-law. Some municipalities have decided to include this in their own CIPs (MMAH, n.d.). Development charges are legislated under the Development Charges Act, 1997 (MMAH, n.d.). Here as well, the development charge fee is paid at the start of the project by the developer or land owner when acquiring the development permit, and is later reimbursed, either in part or all of the fee (MMAH, n.d.). As opposed to the above financial assistance tools, development charge reductions, under Section 28 of the Planning Act, are offered relatively early in the brownfield redevelopment process, in comparison to most other financial tools that are offered (later on) once the project is complete (MMAH, n.d.).

\section{$\underline{3.3-T r e n d s ~ a m o n g ~ O n t a r i o ~ M u n i c i p a l i t i e s ~}$}

According to the MMAH, as of October 1, 2010, 44 municipalities in Ontario have adopted CIPs which contain brownfield provisions (MMAH, n.d.). These municipal financial tool kits for brownfield redevelopment can include any of the aforementioned financial aid options. Table 2 refers to the total number of each individual financial tool being offered in a CIP across Ontario municipalities. 
Table 2: Number of Ontario municipalities offering various CIPs with brownfield provisions as of October, 2010

\begin{tabular}{|r|c|c|}
\hline Type of Financial Incentive & $\begin{array}{c}\text { Number of } \\
\text { Municipalities }\end{array}$ & $\begin{array}{c}\text { Percent of All Municipalities } \\
\text { with “Brownfields CIPs” (44) }\end{array}$ \\
\hline Tax Increment Equivalent Grant & 41 & $93 \%$ \\
\hline Tax Assistance & 34 & $77 \%$ \\
\hline Study Grant Program & 26 & $59 \%$ \\
\hline Development Charges Reductions/Exemptions & 24 & $55 \%$ \\
\hline Fees Grant Program & 21 & $48 \%$ \\
\hline Façade Grant or Loan Program & 15 & $34 \%$ \\
\hline Rehabilitation and Redevelopment Grants/Loans & 4 & $9 \%$ \\
\hline
\end{tabular}

Source: (MMAH, n.d.)

To see a geographical representation of all Ontario municipalities which have adopted CIPs with relevant brownfield provisions, see Figure 1. Further research would be needed to better understand the association between geography and brownfield policy; however, the map illustrates the range of municipalities across Ontario facing the brownfield redevelopment problem.

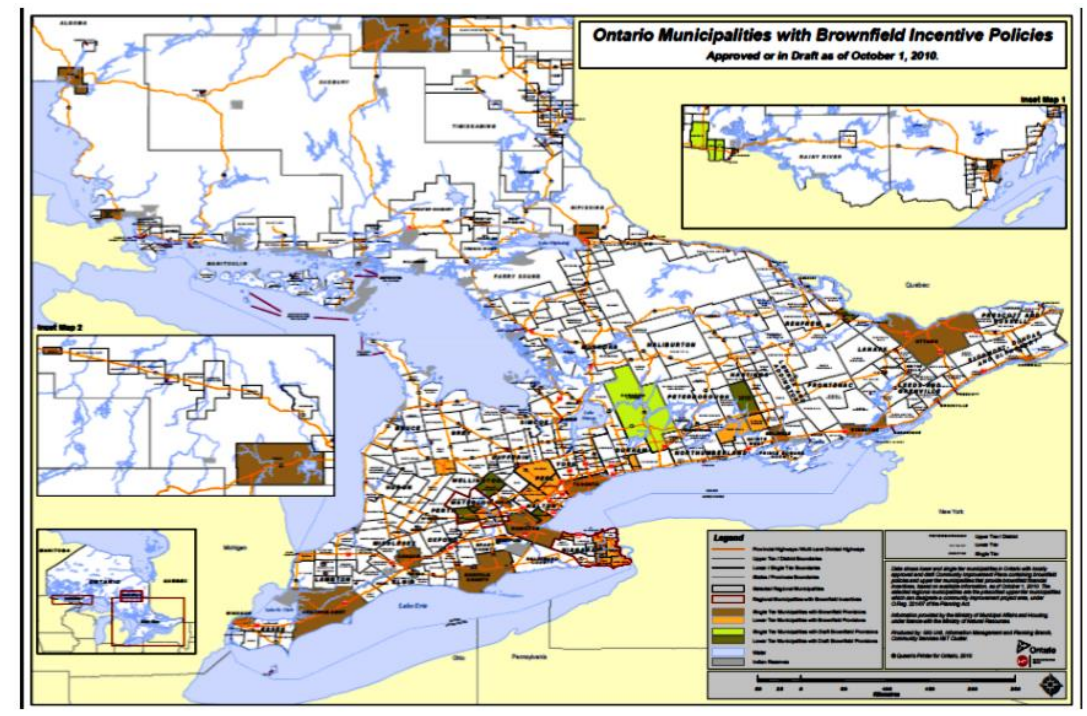

Figure 1:- Geographical representation of Ontario municipalities with brownfield incentive policies

Source: (MMAH, n.d.) 
Although more information would be needed to clarify the exact relationship between brownfield policy and geographical location, certain patterns can be identified from the map. The first and most important observation is the clustering of CIPs with brownfield provisions located along the shorelines of the Southern Great Lakes (MMAH, n.d.). It is reasonable to conclude that this clustering occurs specifically along this area due to associated historical industrial past. This is especially true in the Golden Horseshoe and the north shores of Lake Ontario and the St. Lawrence River, where high concentrations of contaminants would likely be found at the sites of former industries associated with the Great Lakes (MMAH, n.d.). With a greater likelihood of contaminated sites due to prior industrial activities, we can rationally assume that more policy in terms of CIPs containing brownfield provisions would be situated in these areas. The greater potential for brownfield contamination should provide more impetus for a policy response (MMAH, n.d.).

Figure 1 also displays an association of CIPs with brownfield provisions in regional centres with greater populations. Brownfields could potentially exist in all areas that have had some industrial or commercial past; however, we can also notice that the highest frequency of CIPs containing brownfield provisions or draft ClPs in the process of being approved occur in areas of greater populations (MMAH, n.d.). Toronto, Ottawa, Brampton, London and Hamilton are Ontario's largest urban centres and correspond to the larger population groups (MMAH, n.d.). Extensive industrial pasts may coincide with larger populations and areas with more resources and capacity (MMAH, n.d.). It is argued that, because these areas exhibit more robust markets, this will in turn lead to larger and denser developments leading to potentially more brownfield sites being situated in that market (MMAH, n.d.).

\subsection{Region of Waterloo CIP}

The Region of Waterloo is considered an upper-tier municipality in Ontario which offers brownfield incentive programs in its CIP. The Region of Waterloo also has a collaborative relationship 
with its lower-tier municipalities' CIPs to implement most programs offered. Established on January $1^{\text {st }}$, 1973, the Region of Waterloo includes seven lower-tier municipalities; the cities of Cambridge, Kitchener, and Waterloo and the Townships of North Dumfries, Wellesley, Wilmot, and Woolwich (City of Waterloo, 2014). The Region of Waterloo has a collaborative relationship with the lower-tier municipalities in terms of the grants and loans made available; however, this relationship does have its (limitations) exceptions. The two main exceptions are that development charge reductions or exemptions, as well as phase two environmental site assessment (ESA) grants can only be administered by the upper-tier municipality of Waterloo (MMAH, n.d.).

The relationship between upper and lower tier municipalities for grants and loans outside of the exceptions is simple; upper-tier municipalities can participate in the lower-tiers' CIP grants and loans programs, and vice versa (MMAH, n.d.). This relationship is administered under section 28 of the Planning Act, which states that an upper-tier municipality may make grants or loans to lower-tier municipalities for the purpose of carrying out the CIP such that the municipality which makes these grants or loans has provisions that allow it to make such decisions (MMAH, n.d.). Through this association, upper-tier municipalities such as the Region of Waterloo can decide on the feasibility of making available grants or loans to lower-tier municipalities for brownfield remediation even if the upper-tier municipality does not have an established CIP program with brownfield provisions (MMAH, n.d.). The Region of Waterloo is an example of an upper-tier municipality, which under the Planning Act, is guided by regulations allowing it to designate CIPAs and CIPs for the entire region (MMAH, n.d.). However, this relationship does have its limitations. Upper-tier municipalities are (only) permitted to use this regulation for infrastructure projects in their jurisdiction. Land and buildings within and adjacent to existing or planned transit corridors that have the potential for higher density mixed-use development can also use it, a category which brownfield remediation and redevelopment falls under (MMAH, n.d.). The Region of Waterloo, as an upper-tier municipality, can also participate in tax cancellation or other 
tax assistance programs by providing grants and loans for the purposes of carrying out a CIP (MMAH, n.d.).

The Region of Waterloo has also created the "Brownfields Working Group" in 2008, responsible for coordinating, administering, marketing, improving and monitoring the incentive programs offered for brownfield redevelopment while also illustrating the challenges and future opportunities associated with brownfield redevelopment (MMAH, n.d.). This group is comprised of representatives from the Region of Waterloo and its seven lower-tier municipalities (MMAH, n.d.). The regional government also partners with its lower-tier municipalities to offer a Joint Regional and Area Tax Increment Grant; this is currently only available in the cities of Cambridge and Kitchener which both have approved CIPs with brownfield provisions (MMAH, n.d.).

The Region of Waterloo also administers the "Brownfields Financial Incentive Program" offering financial assistance throughout the development process when redeveloping potentially contaminated lands; brownfield developers can be approved to receive grants for phase two ESA studies, as well as grants made available for regional development charges (MMAH, n.d.). Finally, the Region of Waterloo also has a CIP containing brownfield provisions for an area known as the central transit corridor (CTC); a designated area for rapid future transit development and coincidentally the area where the hypothetical scenarios for the current study's development appraisals take place. For a complete analysis of what CIPs are offered in the Region of Waterloo (Cities of Cambridge, Kitchener, Waterloo and its four townships) refer to Table 3. 
Table 3 - Brownfield Incentive Policies offered in the Three Main Cities and Townships within the Region of Waterloo, Ontario.

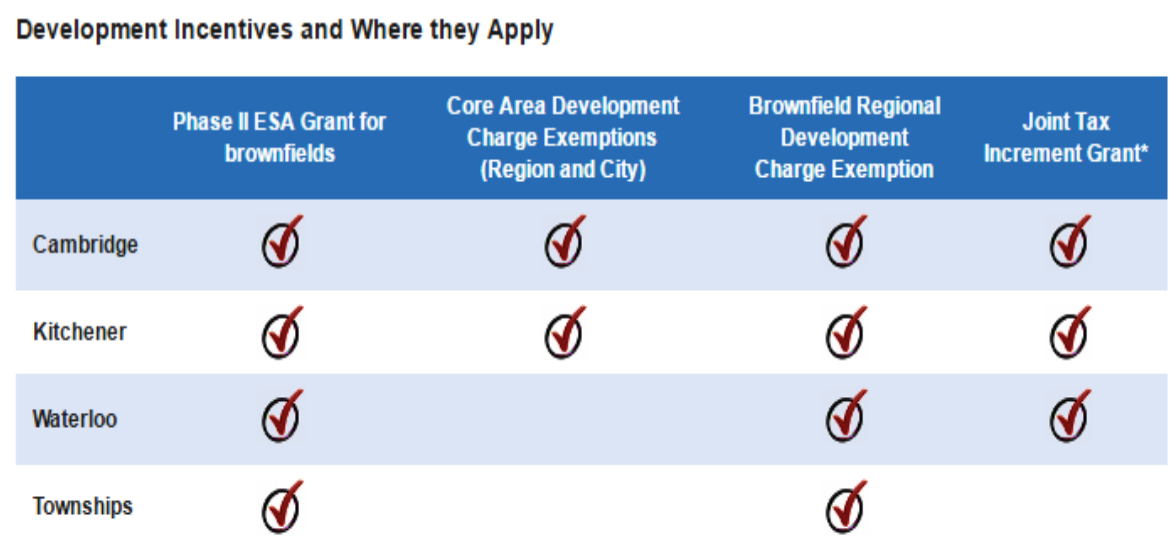

Source: (MMAH, n.d.)

In conclusion, the brownfield problem exists across Ontario and as a result, many financial and non-financial incentive programs have been offered by municipalities for brownfield redevelopment as an incentive for rejuvenating neighbourhoods (MMAH, n.d.). The most common financial incentives offered for brownfield redevelopment in Ontario are tax increment equivalent grants (TIEGS). However, it is important to note that much of this financial aid is offered at the end of the redevelopment process. Up-front grants or loans before the project's start are not as common. Research conducted by the MMAH on brownfield redevelopment does draw attention to the fact that using financial support, coupled with non-financial incentives such as proper marketing strategies and co-operative arrangements between developers and municipalities can greatly impact the rate at which brownfields are redeveloped and thus are put back into productive use (MMAH, n.d.). 


\section{Chapter 4 - Market Analysis / Marketability Study}

This section identifies the market analysis and marketability study which was undertaken to determine the project's viability in the City of Waterloo.

\subsection{Market Analysis}

The current study is a market analysis of the feasibility of redeveloping brownfield sites into multi-unit residential buildings. Given the characteristics of supply of brownfields and the demand for development, the purpose of this chapter is to show the opportunities of sustainable development via brownfield remediation and redevelopment in the City of Waterloo.

To establish a quantitative representation depicting the feasibility of this sustainable development option from a private sector perspective, the use of a development appraisal for the proposed project will be created. The purpose for a development appraisal, otherwise commonly known as a pro forma, is to provide an accounting (style) or quantitatively based projection of a property's cash flow over time to predict the financial investment success. Pro formas take into account many financial metrics which serve as key indicators illustrating the future/expected financial benefits that could arise from a development. However, in order to validate the need for a pro forma at the outset, certain economic and demographic factors must be considered such as the supply and demand of multifamily developments in the region, as well as population changes, income levels, vacancy rates and any other factors that could help or hinder the success of the development. Once we establish the need for investment into multifamily development, then we can look at the applicability of sustainable development through the use of brownfields compared to greenfields.

\subsection{Supply Analysis}


The supply analysis section identifies the inventory of existing multifamily developments within the Region of Waterloo to illustrate the existing supply within this secondary market.

\subsubsection{Inventory and Quality of Existing and Future Multifamily Developments}

The supply of new and existing multifamily buildings has been steadily increasing leading to an increased supply of multifamily dwellings in the Ontario marketplace. According to Statistics Canada, where information is sourced from the Canada Mortgage and Housing Corporation, and filtered to only represent apartment type developments, housing starts and housing completions for multi-unit developments have increased from 2014 to 2015 in Ontario. From Q4 (Q represent an economic quarter of a year) 2014 to Q1 2015, housing starts and housing completions experienced an aggressive expansion factor at $1.35 \mathrm{X}$ and $3.72 \mathrm{X}$ respectively over that time period (Statistics Canada, 2016). Statistics for housing under construction did decline from Q1 2014 to Q3 2015, but reversed this trend heading into Q4 2015 (Statistics Canada, 2016). The total number of multi-unit residential developments across Ontario is increasing the total supply provided to the marketplace, but for the purpose of this study, an analysis on the supply of multi-unit dwellings in the secondary market of Waterloo must be undertaken.

Table 4 - Apartment Housing Estimates in Ontario, Canada Mortgage and Housing Corporation 2014 2015

\begin{tabular}{|c|c|c|c|c|c|c|c|c|}
\hline \multirow{2}{*}{ Housing estimates } & \multicolumn{4}{|c|}{2014} & \multicolumn{4}{|c|}{2015} \\
\hline & Q1 & Q2 & Q3 & Q4 & Q1 & Q2 & Q3 & Q4 \\
\hline Housing starts & 5,759 & 6,237 & 5,199 & 5,531 & 7,461 & 7,371 & 10,264 & 7,578 \\
\hline Housing under construction & 69,095 & 68,999 & 69,364 & 69,627 & 57,966 & 55,876 & 58,768 & 60,321 \\
\hline Housing completions & 4,238 & 6,363 & 5,084 & 5,196 & 19,312 & 9,320 & 7,346 & 5,956 \\
\hline
\end{tabular}

Source: (Statistics Canada, 2016) 
As can be seen from Table 5, for the cities of Kitchener, Cambridge, and Waterloo, apartment buildings greater than five-stories accounted for $10.2 \%$ of all dwelling types; a lower proportion compared to Ontario where they represent $16.2 \%$ of all dwelling types. Single detached homes remains as the largest sector for all dwelling types accounting for nearly $55.8 \%$ of total dwelling units in Waterloo (Statistics Canada, 2016).

Table 5 - Proportional percentages of dwelling types in the region of Waterloo, Ontario and Canada

\begin{tabular}{|c|c|c|c|c|c|c|}
\hline \multirow[b]{2}{*}{ Structural type of dwelling } & \multicolumn{2}{|c|}{$\begin{array}{l}\text { Kitchener - Cambridge - } \\
\text { Waterloo }\end{array}$} & \multicolumn{2}{|c|}{ Ontario } & \multicolumn{2}{|c|}{ Canada } \\
\hline & number & $\%$ & number & $\%$ & number & $\%$ \\
\hline Total - Structural type of dwelling & 181,495 & 100.0 & $4,887,510$ & 100.0 & $13,320,615$ & 100.0 \\
\hline Single-detached house & 101,215 & 55.8 & $2,718,880$ & 55.6 & $7,329,150$ & 55.0 \\
\hline Semi-detached house & 11,970 & 6.6 & 279,470 & 5.7 & 646,240 & 4.9 \\
\hline Row house & 20,030 & 11.0 & 415,230 & 8.5 & 791,600 & 5.9 \\
\hline $\begin{array}{l}\text { Apartment, building that has five or more } \\
\text { storeys }\end{array}$ & 18,530 & 10.2 & 789,975 & 16.2 & $1,234,770$ & 9.3 \\
\hline $\begin{array}{l}\text { Apartment, building that has fewer than } \\
\text { five storeys }\end{array}$ & 24,020 & 13.2 & 498,160 & 10.2 & $2,397,555$ & 18.0 \\
\hline Apartment, duplex & 5,080 & 2.8 & 160,460 & 3.3 & 704,485 & 5.3 \\
\hline Other single-attached house 10 & 320 & 0.2 & 9,535 & 0.2 & 33,310 & 0.3 \\
\hline Movable dwelling 11 & 325 & 0.2 & 15,795 & 0.3 & 183,510 & 1.4 \\
\hline
\end{tabular}

Source: (Statistics Canada, 2015)

Nonetheless, the supply of multifamily dwellings is continually increasing for both Ontario and the three main cities within the Region of Waterloo. The feasibility of multi-unit residential development is not yet fully acknowledged solely from supply characteristics; according to basic economic principles, a growing supply requires a growing demand to ensure market occupancy and market rent are met.

\subsubsection{National and Region-Wide Investment in Multifamily Developments}


Investment in multifamily construction continues to steadily rise nationally, which should increase the supply in the marketplace for many regions in Canada. According to CBRE Market Research from the first half of the 2015 calendar year, total multifamily investment nationwide amounted to $\$ 2.2$ billion, an increase of $26.2 \%$ from the previous year (CBRE, 2015a). This trend continued into the second half of 2015 in a more aggressive manner. A near-record breaking investment volume was achieved in 2015 and $60.7 \%$ of this increase occurred in the latter half of the year. However, it is important to note that much of this investment expansion occurred in primary markets such as Montreal and Toronto and not as much in secondary markets like the Region of Waterloo (CBRE, 2015a). Investment for multifamily dwellings did increase for the Region of Waterloo as the 2015 year progressed. Investment sales volume rose from $\$ 66.5$ million to $\$ 126.9$ million at year end representing a $2.5 \%$ increase from last year (CBRE, 2015b). The current and future supplies of multi-unit residential developments are increasing and if demand can be met for this increased supply, the validity of the study's hypothetical development scenario can be justified in reality.

Table 6 - CBRE Rental Unit Market Statistics Across Canada

\begin{tabular}{|c|c|c|c|c|c|c|c|}
\hline Metro Area & $\begin{array}{r}\text { Vacancy } \\
\text { Oct. } 2015 \\
(\%)\end{array}$ & $\begin{array}{r}\text { Vacancy Rate } \\
\text { Change } \\
\text { Y-o-Y (bps) }\end{array}$ & $\begin{array}{r}\text { 2-BR Monthly } \\
\text { Rent (\$) } \\
\text { Oct. 2015 }\end{array}$ & $\begin{array}{r}\text { Rental Rate } \\
\text { Change } \\
\text { Y-o-Y (\%) }\end{array}$ & $\begin{array}{r}2015 \\
\text { Investment } \\
\text { Sales Volume } \\
\text { (\$ millions) }\end{array}$ & $\begin{array}{r}\text { Change in } \\
\text { Volume Y-o-Y } \\
(\%)\end{array}$ & $\begin{array}{r}2015 \\
\text { Number of } \\
\text { Transactions }\end{array}$ \\
\hline Calgory & 5.3 & 390 & $1,332.00$ & 0.8 & 216.0 & 6.7 & 49 \\
\hline Edmonton & 4.2 & 250 & $1,259.00$ & 2.6 & 398.8 & 48.0 & 53 \\
\hline Halifax & 3.4 & (40) & $1,048.00$ & 4.3 & 59.9 & $(50.5)$ & 12 \\
\hline London* & 2.9 & 0 & 963.00 & 2.1 & 92.5 & 210.4 & 15 \\
\hline Montreal & 4.0 & 60 & 760.00 & 2.8 & $1,490.4$ & 83.2 & 217 \\
\hline Ottawa* & 3.4 & 80 & $1,174.00$ & 3.7 & 285.3 & (28.2) & 43 \\
\hline Toronto ${ }^{*}$ & 1.6 & 0 & $1,288.00$ & 3.0 & $1,630.9$ & 38.6 & 191 \\
\hline Voncouver ${ }^{*}$ & 0.8 & (20) & $1,368.00$ & 4.3 & $1,231.2$ & 131.0 & 134 \\
\hline Waterloo Region* & 2.4 & 10 & 997.00 & 2.3 & 126.9 & 2.5 & 27 \\
\hline Winnipeg* & 2.9 & 40 & $1,045.00$ & 2.9 & $\mathrm{~N} / \mathrm{A}$ & N/A & N/A \\
\hline Total & 3.1 & 80 & $1,123.40$ & 2.9 & $5,531.9$ & 50.9 & 741 \\
\hline
\end{tabular}

Source: (CBRE, 2015b) 
Because of the rapid expansion of national multifamily investment in the first half of 2015, CBRE market research predicted new multifamily housing value in 2015 would exceed the \$4 billion mark, making it one of the best years on record for multifamily investments but falling short of the $\$ 6$ billion reached in 2012 (CBRE, 2015a). Canadian multifamily real estate has received lots of attention and not just from private foreign buyers but also from institutional establishments. The Canadian Pension Plan Investment Board (CPPIB) endured its first Canadian multifamily transaction which closed in Q2 of 2015 (CBRE, 2015a). The Canadian multifamily real estate market has also been gathering significant investment from Real Estate Investment Trusts (REITs) and Real Estate Operating Companies (REOCs) which at year end, accounted for 39.4\% of transactions (CBRE, 2015a). Private Canadian investors accounted for $41 \%$ of all multifamily transactions in the second half of 2015 (CBRE, 2015b). From a yearover-year perspective, investment volume in multifamily dwellings increased by $71.6 \%$ from the second half of 2014, illustrating a significant trend; the increased demand from the private sector to invest in multi-unit real estate as a lucrative and feasible investment option.

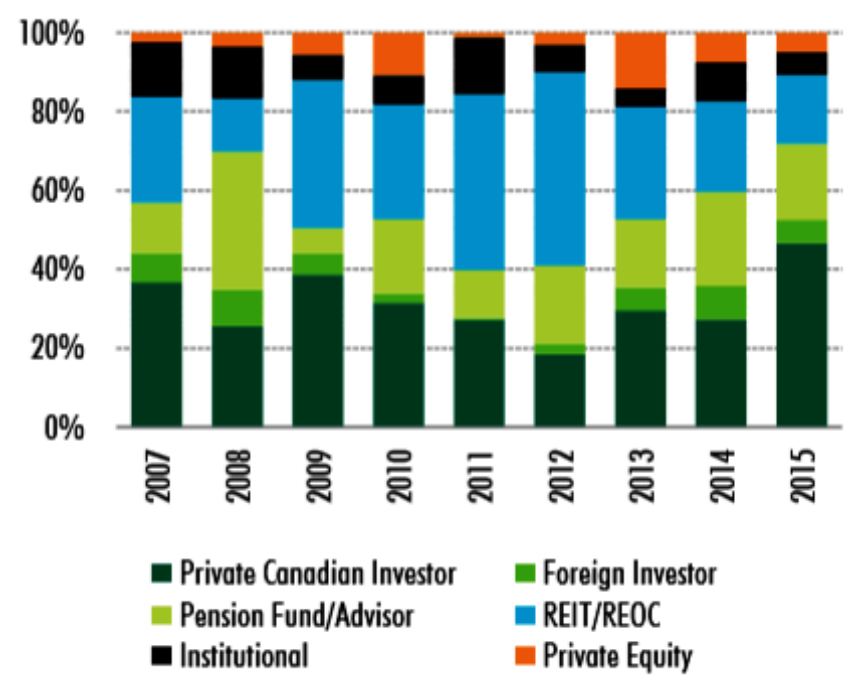

Figure 2 - Types of Purchasers for Canadian Real Estate Transactions above $\$ 10$ million Source: (CBRE, 2015c) 
Recent volatility in global markets and concerns among investors about the global economy made investors worried about which investment market to participate in. According to CBRE market research, as a result of the increasing volatility and concern about global markets, institutional investor's as well high net-worth individuals and even pension funds have redirected their wealth and seek highquality assets which can provide stable returns (CBRE, 2015c). For example, investments in Canadian real estate by pension funds have increased in total holdings since 1990 (refer to figure 3). This has benefited the Canadian commercial real estate market because in Q4 of 2015, investment volume reached a high not seen since 2007, reaffirming the confidence investors have in the Canadian real estate market (CBRE, 2015c). National 2015 figures show that multifamily dwellings accounted for roughly $22 \%$ of the total national investment volume in the Canadian real estate market (CBRE, 2015C). Real estate assets can even provide investors with returns greater than that of the traditional equity indices (S\&P/TSX Composite Index) (CBRE, 2015c). The CBRE market research also expects this trend to intensify in 2016 because of many expected deals to close in H1 2016 (CBRE, 2015c).

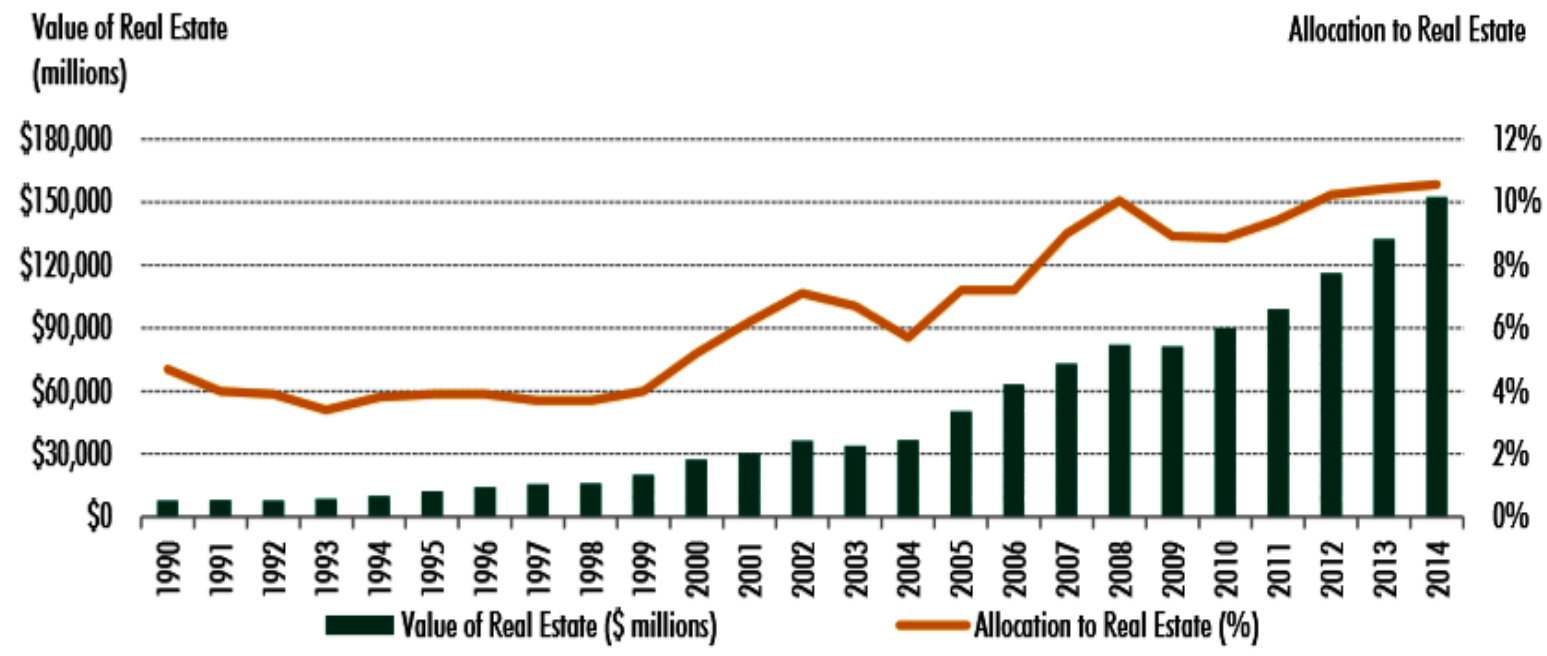

Figure 3 - Pension Fund Allocations over time in Canadian Real Estate Markets Source: (CBRE, 2015c) 


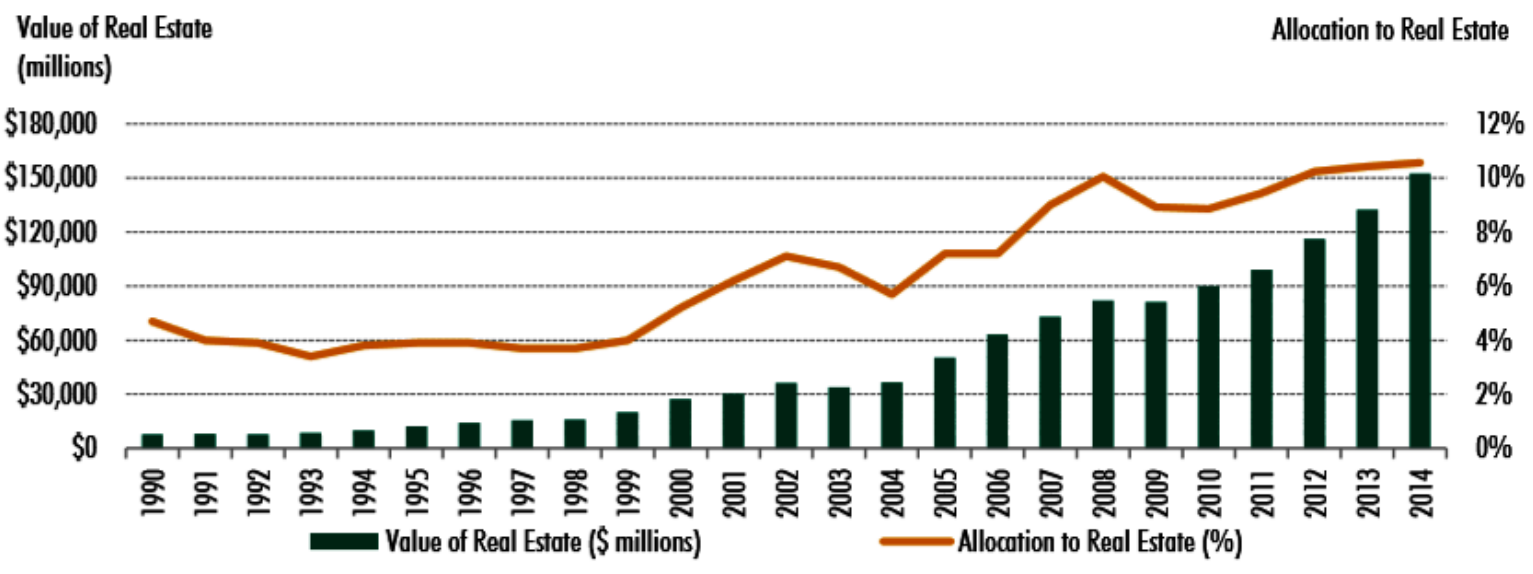

Figure 4 - Value and Allocation Comparisons to Real Estate, Region of Waterloo

Source: (CBRE, 2015c)

For the Region of Waterloo, multifamily dwellings represent the largest sector for all types of developments. Total Q4 2015 investment in the Region of Waterloo market amounted to \$192.3 million; multifamily dwellings represented $\$ 126.9$ million, representing roughly $66 \%$ of that total. This value, however, is still small in comparison to the investments in multifamily dwellings in other parts of Canada and some cautionary concern should be highlighted as increased construction and investment into multifamily dwellings could potentially oversaturate or oversupply the marketplace. However the analysis of an over-supplied marketplace cannot be concluded solely by looking at supply but by also assessing demand. The continued flow of investment into multifamily dwellings in the Region of Waterloo can still prove to be fruitful investment and development option if met by a growing demand for multi-unit residential development.

\subsection{Demand Analysis}

This section describes the demand analysis for multifamily residential dwellings in the Region of Waterloo. 


\subsubsection{Vacancy Rates and Space Absorption}

Vacancy statistics are a very important factor in understanding the demand and occupancy of multifamily residential real estate nationwide. Understanding the trends in vacancies for multifamily developments aids our understanding of existing space absorption and usage (which expresses demand) which is incorporated into the pro forma to generate potential revenue streams for the hypothetical development scenario. According to the CBRE Market Research for multifamily dwellings, national vacancy rates have steadily increased throughout the year 2015; in the first half of 2015, the vacancy rate had increased to $2.8 \%$, a figure which was just above the 10 -year average but 20 base points (bps) from a year ago (CBRE, 2015a). By the year end, national vacancy rates had risen to $3.1 \%$ which was last seen in 2009 (CBRE, 2015b). These national statistics need to be read with caution: eliminating Calgary and Edmonton would lower the rate to $2.7 \%$ because a major contributor to the increased vacancy rate can be attributed to the negative impact of lower oil prices and worsening employment conditions (CBRE, 2015b).

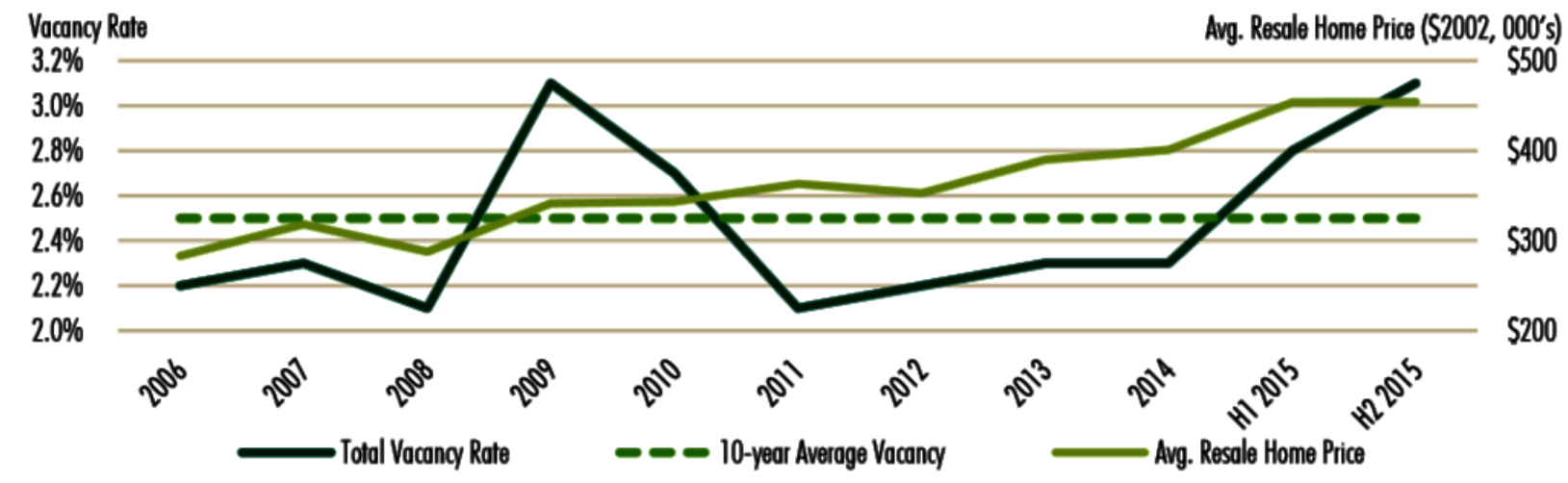

Figure 5 - National Trends in Multifamily Vacancy Rate Source: (CBRE, 2015b)

These elevated national vacancy rates (representing a decreasing demand nationally) coupled with increased supply could raise alarms if the market becomes oversupplied; economic equilibrium 
would be disturbed and price fluctuations would occur to find the new equilibrium price in the marketplace. Such observations are starting to become apparent; two-bedroom suites had the highest vacancy (3.4\%) for all the different multifamily units available, and as a result, average rents rose by 2.9\% for two-bedroom suites over the last year (CBRE, 2015b). Vacancy rates within the Region of Waterloo are less than the national average and this could represent a higher demand for multifamily dwellings, representing a 2.4\% vacancy rate in 2015 (CBRE, 2015b). With vacancy levels still in the low single digits, and with record high asset prices for multifamily dwellings, developers can still find profitable opportunities in multifamily developments; the hypothetical scenarios, through the use of a pro forma, will illustrate the feasibility of this opportunity through brownfield redevelopment using vacancy rates being experienced currently in the Region of Waterloo market.

\subsubsection{Population Demographics}

As of 2011, census data from Statistics Canada indicate that the population in the City of Waterloo accounted 98,780 people (Statistics Canada, 2016b). Comparing this figure to the 2006 Census Report, the City of Waterloo experienced a 1.3\% increase in population (Statistics Canada, 2016b). However, looking simply at the number of people residing in a region is an incomplete analysis of how dense or saturated the area is in terms of people residing per square kilometer. The City of Waterloo only occupies 64.02 square kilometers but has a population density of 1,542.9 people per square kilometer (Statistics Canada, 2016b). Dense populations residing on limited land space could represent enormous opportunities for developers to develop vertically rather than horizontally and thus could represent a greater opportunity of success when building multifamily residential complexes compared to single dwelling family homes. 


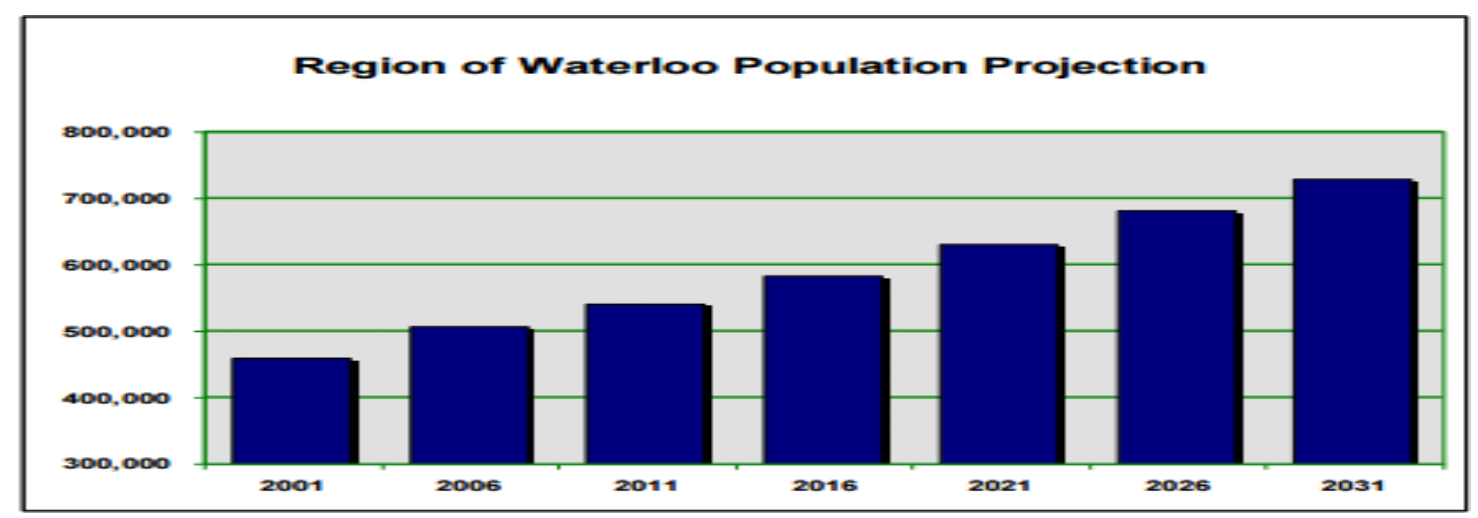

Figure 6 - Region of Waterloo Population Projections

Source: (Region of Waterloo, 2011)

\begin{tabular}{|c|c|c|c|c|c|c|c|c|c|c|}
\hline \multirow[b]{2}{*}{ Geographic name } & \multirow[b]{2}{*}{ Type 1} & \multicolumn{3}{|c|}{ Population } & \multicolumn{2}{|c|}{ Private dwellings, 2011} & \multirow[b]{2}{*}{$\begin{array}{r}\text { Land area in } \\
\text { square } \\
\text { kilometres, } 2011\end{array}$} & \multirow[b]{2}{*}{$\begin{array}{r}\text { Population density } \\
\text { per square } \\
\text { kilometre, } 2011\end{array}$} & \multicolumn{2}{|c|}{$\begin{array}{c}\text { CMA, CA, CSD } \\
\text { population rank, } \\
2011\end{array}$} \\
\hline & & 2011 & 2006 & $\begin{array}{r}\% \\
\text { change }\end{array}$ & Total & $\begin{array}{r}\text { Occupied } \\
\text { by usual } \\
\text { residents }\end{array}$ & & & National & $\begin{array}{r}\text { Prov. I } \\
\text { Terr. }\end{array}$ \\
\hline $\mathbf{4}$ & 7 & $\nabla$ & 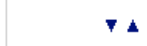 & 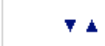 & $\nabla$ & 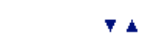 & $\nabla$ & $\nabla$ & $\nabla$ & \% \\
\hline Canada \pm & & $33,476,688$ & $31,612,897$ & 5.9 & $14,569,633$ & $13,320,614$ & $8,965,121.42$ & 3.7 & & \\
\hline $\begin{array}{l}\text { Kitchener - } \\
\text { Cambridge - } \\
\text { Waterloo }\end{array}$ & CMA & 477,160 & 451,235 & 5.7 & 191,739 & 181,493 & 827.43 & 576.7 & 10 & 4 \\
\hline Cambridge & $\mathrm{CY}$ & 126,748 & 120,371 & 5.3 & 47,818 & 46,460 & 113.00 & $1,121.7$ & 38 & 18 \\
\hline Kitchener & CY & 219,153 & 204,668 & 7.1 & 89,603 & 86,374 & 136.79 & $1,602.1$ & 22 & 9 \\
\hline North Dumfries & TP & 9,334 & 9,063 & 3.0 & 3,288 & 3,229 & 187.44 & 49.8 & 424 & 152 \\
\hline Waterloo & CY & 98,780 & 97,475 & 1.3 & 42,984 & 37,517 & 64.02 & $1,542.9$ & 52 & 25 \\
\hline Woolwich & TP & 23,145 & 19,658 & 17.7 & 8,046 & 7,913 & 326.17 & 71.0 & 177 & 67 \\
\hline
\end{tabular}

Figure 7 - Region of Waterloo Population Demographics

Source: (Statistics Canada, 2015b)

An examination of the population changes for the Region of Waterloo (which includes

Cambridge, Waterloo and Kitchener) depicts a rapidly expanding population. Population growth rates

for the three main cities have surpassed both the provincial and national averages (Region of Waterloo,

2011). In 2011, the population for the Region amounted to 542,100 people and is expected to grow to 
729,000 people by the year 2031 (Region of Waterloo, 2011). This equates to a growth of $34 \%$. The fastest growing segment of the population involves senior citizens older than 75 years of age, and this is expected to continue growing because the baby boomer population reached the age of 65 in 2011 (Region of Waterloo, 2011). The demand for multifamily dwellings and senior citizen homes has been documented to be accelerating, and the aforementioned demographics are largely impacting these statistics.

\subsubsection{Income and Employment Demographics}

The most current or available median after-tax income of individuals residing in Waterloo from the 2006 census reports amounts to $\$ 31,617$ and the average after-tax income is $\$ 40,380$ (Statistics Canada, 2015). Median household after-tax incomes were $\$ 67,150$, and average household after-tax income, $\$ 82,301$ (Statistics Canada, 2015). When looking at job sector data for the three main cities within the Region of Waterloo (Cambridge, Waterloo and Kitchener) the situation becomes increasingly worrisome. In 1987, manufacturing and processing jobs were widely available accounting for 50,000 jobs (Region of Waterloo, 2011). Now, they only account for 40,000 jobs and have been replaced by employment in the service sector, administrative, finance and education; jobs which have been known to generate lower wages and fewer benefits (Region of Waterloo, 2011). To further complicate issues, income levels of new immigrants entering the Region of waterloo have also decreased, and savings rates across the entire region have also diminished. The median income from interest on savings only amounted to $\$ 310$ per person in 2008 (Region of Waterloo, 2011). Individuals earning less money and saving less money find home ownership much more difficult to achieve and thus should drive up demand for rental housing.

During the last and most recession, the three main cities within the Region of Waterloo (Cambridge, Kitchener and Waterloo) moved from some of the lowest unemployment rates to some of 
the highest witnessed throughout the entire country (Region of Waterloo, 2011). Another alarming statistic was that between 2001 and 2006, full-time employment decreased by $14 \%$ while part-time employment increased (Region of Waterloo, 2011). However, in 2015 this level of unemployment decreased and future estimates of employment are promising. Employment throughout the entire region is expected to grow to 359,000 jobs by the year 2029, up from the 257,655 jobs in 2006 (Region of Waterloo, 2011). Even though employment conditions are expected to improve, $10.2 \%$ of individuals and $11 \%$ of families in the Region of Waterloo are low income families, and the income gap between individuals and families continues to widen - some individuals will be able to keep up with increasing real estate values, while others will be forced to rent, further increasing rental demand (Region of Waterloo, 2011).

\begin{tabular}{|l|r|r|r|}
\hline Labour force status & & \\
\hline $\begin{array}{l}\text { Total population aged 15 years and over by } \\
\text { labour force status } \underline{\mathbf{8 3}}\end{array}$ & 80,440 & 39,695 & 40,750 \\
\hline In the labour force & 55,215 & 28,825 & 26,395 \\
\hline Employed & 51,230 & 26,790 & 24,445 \\
\hline Unemployed & 3,990 & 2,035 & 1,955 \\
\hline Not in the labour force & 25,225 & 10,870 & 14,350 \\
\hline Participation rate & 68.6 & 72.6 & 64.8 \\
\hline Employment rate & 63.7 & 67.5 & 60.0 \\
\hline Unemployment rate & 7.2 & 7.1 & 7.4 \\
\hline
\end{tabular}

Figure 8 - Region of Waterloo Unemployment and Employment Statistics Source: (Statistics Canada, 2015)

Rising home prices and robust immigration are additional factors making home ownership less and less affordable. National average resale home prices climbed to $12 \%$ in 2015 and with tighter mortgage regulations that took effect February 2016, the affordability gap between home ownership and rentals continues to widen (CBRE, 2015b). Ultimately, home ownership has become increasing more difficult and this should drive up demand in Canada's rental housing market (CBRE, 2015b). 
Subsequently, as a result of this increased demand for rental housing coupled with single digit vacancy rates and rising rents, purpose-built rentals in 2015 reached 21,787 across the nation and comprised $26 \%$ of total multifamily construction (multifamily construction can be in the form of condominiums or rental apartments) (CBRE, 2015b). Purpose-built rentals are up 61\% in 2015 from last year (CBRE, 2015b). Historically, dating back the last 35 years, purpose-built rental construction had been a rarity; $79 \%$ of existing rental housing is at least 35 years old (CBRE, 2015a). New purpose-built construction illustrates the growing demand and supply for rental housing (CBRE, 2015a).

\subsection{Marketability of Product}

Once a market analysis is completed and the supply and demand is established for multifamily dwellings in the secondary market of Waterloo Ontario, the next step is to look at the marketability of that product. It would be an incomplete analysis to examine only the supply and demand of multifamily dwellings. It is necessary to profile the type of dwelling and its suitability in the City of Waterloo. In doing so, this study will examine the profile and property types for the intended locations, the quality of the product and the amenities to be offered, as well as indicating the market rents across the City of Waterloo and other neighbouring jurisdictions.

\subsubsection{Location Parameters}

Multifamily dwellings refer to both condominiums as well as rental apartments. The focus of this development appraisal will revolve around the construction of a rental apartment building taking place on a brownfield site. The building will be located in the secondary market of Waterloo, and will be within close proximity to two of Ontario's major universities, The University of Waterloo and Wilfred Laurier University. This is an ideal location as most students living abroad in the City of Waterloo will seek rental apartments for the duration of their educational career. The development will also be located in the Central Transit Corridor of Waterloo where the Waterloo Regional LRT is being 
constructed and due for completion in 2018 (Region of Waterloo, 2011). Annual transit ridership in the region has continually increased and will continue to do so in the near future; annual transit ridership accounted for 9.5 million in the year 2000 and increased to 16.5 million by 2009 , representing a $74 \%$ increase or a $6.3 \%$ increase annually (Region of Waterloo, 2011). A forecast of future demand in annual transit ridership predicts that transit infrastructure will need to be expanded by $25 \%$ by 2031 to meet the increased demand. The aforementioned location parameters indicate that both the Region and City of Waterloo is a growth market and the thus demand for rental apartments should continue to increase.

Brownfield remediation in the City of Waterloo will also help make this a more desirable living place because of the greater protection to the environment. Brownfield remediation will improve air and water quality within the region. The expansion of public transit should also help reduce greenhouse gas emissions into the environment by reducing the number of cars travelling on the road; the Ontario Ministry of the Environment and Climate Change estimate that $65 \%$ of air emissions can be sourced from the transportation sector (Region of Waterloo, 2011). The Region of Waterloo has also initiated a program to help protect and preserve the limited water resources; this is known as the Source Water Protection Plan and the Ontario government passed the Clean Water Act in 2006 to help protect drinking water sources. It is evident that the Region of Waterloo has real environmental sensitivity concerns to be aware of which should further promote the redevelopment of potentially contaminated lands.

Other redevelopments within the Region of Waterloo currently taking place are also making this secondary market a more desirable place to live. The Region of Waterloo is currently updating the Victoria Hospital and is also taking part in a rejuvenation project of London's SOHO heritage district (Region of Waterloo, 2011). Overall, all location parameters discussed should increase the desirability of the Region and City of Waterloo as a place to live and should also increase the need for the 
development of rental apartments hopefully taking place in environmental sensitive areas such as brownfields.

\subsubsection{Quality of Product}

The type of rental apartment building to be constructed will be a Class A high-rise apartment. Class A high-rise apartments draw in the largest rental rates by offering the most desirable amenities which are not offered in other rental apartments. Such amenities that could be offered in the hypothetical development include underground parking and outdoor park areas.

\subsubsection{Market Rent Variations}

Looking at market rent variations is another crucial factor aiding developers in understanding the marketability of the product they wish to create. Understanding market rents not only helps depict what rental rates we should expect as sources of revenue, but also help illustrate comparable rental rates in the Region of Waterloo. Average 2-bedroom monthly rents across the nation are currently at $\$ 1,123.40$ and have increased by 2.9\% from 2014 to 2015 (CBRE, 2015b). Highest rental rates in Canada are experienced in the primary markets of Vancouver and Toronto and the lowest rates in Montreal (CBRE, 2015b). Capitalization (CAP) rates across the nation are other vital statistics to which we must pay attention as they help determine the value of the development and the rental rates in which we could anticipate in the future. Those rates for high-rise apartments are now at relatively low levels which should translate into higher prices for investors as well as higher rental rate increases (CBRE, 2015b). National cap rates for high-rise apartments are currently up from Q4 2014 statistics and currently stand at $4.39 \%$ (CBRE, 2015b). Cap rates in the Region of Waterloo are slightly higher and range between 4.75 and $5.25 \%$ and this has no year-over-year change (CBRE, 2015b). The Region of Waterloo does have a higher cap rate than the national rate as well as the rate experienced in Toronto; 
this translates into a lower value for the property which should be anticipated when comparing primary and secondary markets. 


\section{Chapter 5 - Pro forma and Analysis of Results}

\section{1-Development Pro forma Analysis}

This study addresses the effect of brownfield redevelopment policies on the decision to develop a brownfield site, as opposed to a greenfield development opportunity. In order to quantify and directly measure the impact (or sensitivity analysis) of the different incentives offered to municipalities across Ontario and developer sensitivity to different incentives, the pro forma design involved two steps. The first step was to create hypothetical scenarios for actual brownfield and greenfield properties located within the secondary market of Waterloo, Ontario. For both hypothetical situations, the desired development was that of a multi-unit residential apartment building. The only difference between the two hypothetical situations is that one is contaminated and thus has associated remediation and redevelopment costs. Creating identical hypothetical situations allows for a comparison of brownfield and greenfield developments within the same region. The second step was to build pro formas for both hypothetical scenarios in order to quantify and directly evaluate the impacts of investor returns from the different incentives and incentive packages being offered. This method was chosen over a costbenefit analysis simply because this is the type of development appraisal which developers use themselves to determine a project's potential feasibility (De Sousa, 2000). Finally, an analysis of the results will be required to determine whether the CIPs with brownfield provisions are strong enough factors to improve project returns and thus ultimately persuading a developer to take on a form of sustainable development via brownfield remediation and redevelopment.

\section{2. - Hypothetical Development Scenarios}

Creating the hypothetical brownfield scenario involved using an average value method drawn from various brownfield redevelopments that have previously occurred in the City of Waterloo. This information was sourced from various Records of Site Condition (RSC) documents, all of which were 
publicly available on the Ontario Environmental Registry's database. RSC documents must be submitted to the Ontario Ministry of the Environment for redevelopments involving property use changes.

RSC documents contain a wide array of information ranging from the site's area and the purchase price of the property, past potentially contaminating activities and the types of contaminants present, their degrees of contamination, to hydrogeological maps identifying water flows and slopes. Many documents were available in the City of Waterloo and a selection method was applied in order to reduce the number of documents being analyzed. All sites selected had to have RSC documents which fit the screening criteria. The criteria I used to screen were:

- Most RSC documents had similar potentially contaminating activities which took place on the land prior to redevelopment, and thus similar types of contaminants were present such as heavy metals, PAHs, PHCs (F1-F4) and BTEX. All RSC documents which did not identify these as the main contaminants of concern were excluded from the selection process.

- $\quad$ All RSC documents were also submitted within the last fifteen years. Further site and soil characteristics were then applied to reduce the research results; such characteristics were site location, physical properties of soil such as the texture, and a determination on whether the site was of potential environmental concern.

- Sites located in areas of natural significance or sites which required no soil excavation were eliminated.

- These filters were applied because the selected criteria were abundant in all RSC documents and thus provided a fair illustration of the type of contamination present in the study area and furthermore, the documents contained sufficient information about contamination which could then be applied in the pro forma analysis. 
- Greenfield site characteristics did not need to be generated from RSC submitted documents because those were assumed to have no contamination.

- Real estate sources were used to determine the value or purchase price of the greenfield site. It is important to note that the value or purchase price of the greenfield seemed to be too inexpensive ( $\$ 625,000$ for 2.99 hectares) and may not reflect true valuations. Information on available greenfields in the City of Waterloo was scarce and thus caution should be used when noting the purchase price of the greenfield due to the assumption that we used this $\$ 625,000$ for the hypothetical scenario (0.323 hectares in size).

Overall, five different RSC documents were used to gather the necessary data for the brownfield scenario generation. These RSC documents will further be denoted by the RSC submission number. These are the documents which were used: RSC \# 204448, RSC \# 211952, RSC \# 212608, RSC \# 213109, and RSC \# 217746

\section{3. - Pro forma Analysis}

Once the hypothetical development situations could be generated, the next step was to create a pro forma for both the brownfield and greenfield development scenarios. In order to complete this, information had to be obtained from various sources. The purchase price and area of the property was determined from the RSC documents using a simple average, and these numbers were brought into 2016 present term values using the Bank of Canada's (BOC) online inflation factor. Market information was sourced from CBRE Market Research reports and used in combination with information sourced from Statistics Canada. Information collected from both CBRE market research and Statistic Canada included average 2-bedroom (2-BR) monthly rates, vacancy rates, capitalization rates, as well as other market information that was required in the supply and demand analysis. To determine the project's financing options, the Canadian Mortgage and Housing Corporation's financing standards were used to 
determine both the short term construction loan as well as the long term permanent financing loan. The 2016 Altus Construction Cost guide was also used to determine both the hard costs (including parking) and soft construction costs which were used as development costs in the pro forma.

Other costs in the pro forma could not be tallied from public sources as this type of information is not readily available and usually restricted to the private and confidential domain. Thus, certain assumptions were used in the pro forma to calculate these costs and need to be noted:

Assumption 1 - De Sousa's (2000) research also considered a medium contaminated brownfield site which was contaminated by the same contaminants found on the sites in this research (heavy metals, PAHs, PHCs (F1-F4), BTEX). Thus an assumption that the site remediation and assessment costs would be similar on an area basis (per hectare) and could then be calculated into present dollar terms using the BOC's inflation factor.

Assumption 2 - De Sousa's (2000) investigation estimated its demolition costs from case scenarios which had similar sizes and types of developments (for example: commercial building) already occupying the land in the aforementioned RSD documents. This study assumed the same estimated values of demolition for the pro forma and were brought into present dollar terms using the BOC's inflation factor.

Assumption 3 - De Sousa's (2000) study also considered an architectural / engineering / consulting fee for a building development of 114,119 gross square feet. The hypothetical building had a gross square footage 1.46 times that total. The fee for this case was determined by multiplying De Sousa's cost by 1.46 and adjusting the value by the BOC inflation factor to determine its present value.

\subsection{Analysis of Results}


A Net Present Value (NPV) estimate allows a developer to equalize the time value of money in order to compare an investment option today to an investment option into the future (Peiser \& Hamilton, 2012; 13). Because money invested can earn interest, using the NPV formula allowed for the calculation of opportunity costs (represented by the discount rate) of an investment today versus an investment in the future (Peiser \& Hamilton, 2012; 13). The discount rate chosen will affect how investments are compared because the value of cash flow in the future is less than cash flow today. Thus, the less certain a developer is of the future, the more a developer may want to discount that value. Discount rates also take into account the level of risk that a developer would consider acceptable. Generally, land development is considered to be the riskiest form of an investment and thus developers seek the highest reward for taking on the highest levels of risk. Determining the discount rate is also dependent on other variables such as personal investment goals, inflation rates and even interest rates from alternative investment options (Begley, 2014).

NPV is most helpful when a developer wants to determine the price they would pay for an investment in order to receive a specific return over a specific time period. In our analysis, the discount rate chosen will be the same as the rate of return on a 10-year Government of Canada Bond (which is considered to be the safest alternative investment option). In our analysis, the research will compare each NPV against one another for both the brownfield redevelopment and greenfield development options. This NPV value will also be compared to the original purchase price of the land; this will help determine the money a developer saves by deducting the true NPV value of the development compared to the purchase price or site acquisition costs.

The Internal Rate of Return (IRR) on Equity is another concept of investor returns and helps both developers and investors understand the Return on Equity (ROE) that they would be receiving from a leveraged (financed) development project (Peiser \& Hamilton, 2012; 103). Most developers do require a 
ROE that is at least $12-15$ percentage points higher than that of a risk-free 10 year government of Canada bond (typical return in this market), which currently pays out at $1.4 \%$ (CBRE, 2015c). This follows the general rule of thumb in finance which states more risk must be met with more reward. The IRR is defined as the discount rate at which the NPV equates to zero (Peiser \& Hamilton, 2012; 109). The discount rate in the IRR calculation which makes NPV equate to zero can also be viewed in simpler terms as the rate at which an investor is indifferent between two different investment options. Thus, for example, if an IRR of $20 \%$ is received from a residential building development in one investment option, the alternative (Government of Canada Bond) would have to pay out a return of $20 \%$ for an investor to be indifferent between both investment opportunities. For the purpose of this analysis, the IRR values from both the brownfield and greenfield development options will be compared to determine the more financially lucrative investment option. Comparing these IRR values to those which are expected by developers and investors in real world applications will define the opportunities that both brownfield and greenfield developments provide as well as distinguishing between the better investment option. Finally an analysis on the changes to these IRR values from the brownfield incentives provided will highlight the main purpose of this research and help in the determination of the effectiveness of such incentive policies.

A NPV calculation does offer a better method for ranking different projects than an IRR determination because it provides the value in today's dollars from the wealth that the project is expected to generate in the future (Peiser \& Hamilton, 2012; 110). The project with the greatest NPV is the preferred investment or development option. However, solely looking at NPV statistics can be misleading. Developers or investors could manipulate the numbers to make the NPV seem more attractive (Peiser \& Hamilton, 2012). Thus both NPV and IRR calculations will be included in this research. 
The brownfield redevelopment project with no incentives applied to the pro forma revealed that this type of development project in the City of Waterloo was feasible. Given the assumptions, the project produced an expected market return of $12 \%$ for the IRR on equity. However, when compared to a greenfield development, the project returns were not as large (17\% IRR on equity) and this is assumed to be due to the lack of site assessment and remediation costs associated with brownfield contamination. Furthermore, the greenfield project does not entail any level or risk in regard to contaminant cleanup and future contamination liabilities which cannot be measured quantitatively. Fear of discovering some other contamination during remediation was evident in the investor and developer interviews as a common roadblock to brownfield redevelopment (De Sousa, 2000). From a developers viewpoint (where average desired levels of return on investment should be roughly $12-15 \%$ higher than that of a 10-year GOC bond), the brownfield developments expected IRR on equity did fall short from industry standards, whereas the greenfield development produced a more acceptable result with no associated levels of risk from contamination.

Table 7 - Brownfield and greenfield developments without CIP incentives applied

\begin{tabular}{|l|l|l|}
\hline Land Type & NPV $(\$)$ & IRR (\%) \\
\hline Brownfield & $10,920,437.76$ & 12 \\
\hline Greenfield & $10,466,230.49$ & 17 \\
\hline
\end{tabular}

A more important question for the purpose of this investigation is which incentive measures will have the greatest impact or parameter sensitivity on these return calculations, and thus will aid in understanding what incentives are best suited for promoting brownfield redevelopment as opposed to greenfield developments. This research will analyze the individual impacts of each incentive measured as well as the combined effects created by incentive packages.

The City of Waterloo currently offers three different incentives with brownfield provisions in their outlined community incentive program (CIP) (MMAH, n.d.). These include a 50\% phase 2 ESA grant, 
RDC exemptions and Joint TIEGS which are outlined in the BFIP guidelines (MMAH, n.d.). Each measure was incorporated into the pro forma analysis separately to analyze its individual impacts.

Table 8 - NPV and IRR changes for brownfield development with Waterloo approved CIP incentives

\begin{tabular}{|l|l|l|}
\hline Incentive & New NPV (\$) & New IRR (\%) \\
\hline $50 \%$ Phase 2 ESA Grant & $10,926,537.27$ & 12 \\
\hline $100 \%$ RDC Exemption & $12,199,602.29$ & 16 (+4 change) \\
\hline $50 \%$ RDC Exemption & $11.560,020.02$ & $14(+2$ change) \\
\hline $\begin{array}{l}\text { Joint TIEGS (up to a maximum } \\
\text { of } 10 \text { years) }\end{array}$ & $11,657,220.29$ & $14(+2$ change) \\
\hline
\end{tabular}

The results indicate that, for all the above CIPs with brownfield provisions, one-time grant payouts from the RDC exemption incentive had the greatest impact on NPV and IRR. However, in practice, RDC exemptions can be all or partly refunded and thus a 50\% RDC exemption was also analyzed. This $50 \%$ RDC exemption produced the second largest individual impact in our analysis of IRR and the third largest NPV. The RDC exemption payout produced the highest sensitivity at $100 \%$ exemption. The tax assistance program such as the Joint TIEGs, which are offered on a yearly basis up to a maximum of 10 years, do impact investor returns less significantly (lower sensitivity) than the 100\% RDC exemption for both NPV and IRR. However, when compared to the $50 \%$ RDC exemption, Joint TIEGs offer the second largest NPV and IRR. The above analysis of results from individual incentives can be seen in table 8.

The City of Waterloo also has the option of offering other incentives that contain brownfield provisions, as these community incentive programs (CIPs) can be tailored for each municipality. Table 9 
below presents the individual impacts from other incentives being offered currently by other municipalities across Ontario.

Table 9 - NPV and IRR changes for CIP incentives not currently being offered in Waterloo, Ontario

\begin{tabular}{|c|c|c|c|}
\hline Incentive & New NPV (\$) & New IRR (\%) & \% Change to IRR \\
\hline $\begin{array}{l}100 \% \text { Full Study Grant } \\
\text { Reimbursement (phase } \\
1 \text { and phase } 2 \text { ESA) }\end{array}$ & $10,935,089.97$ & 12 & \\
\hline $\begin{array}{l}\text { 100\% Full Study Grant } \\
\text { (All site assessment } \\
\text { fees) }\end{array}$ & $10,965,927.96$ & 13 & +1 \\
\hline $\begin{array}{l}\text { Tax Assistance Program } \\
\text { (municipal + education) }\end{array}$ & $10,940,728.41$ & 12 & \\
\hline Façade Grant & $\mathrm{N} / \mathrm{A}$ & $\mathrm{N} / \mathrm{A}$ & \\
\hline $\begin{array}{l}\text { Rehabilitation and/or } \\
\text { Redevelopment Grants }\end{array}$ & $\mathrm{N} / \mathrm{A}$ & $\mathrm{N} / \mathrm{A}$ & \\
\hline $\begin{array}{l}\text { Municipal Fees Grant } \\
\text { Program }\end{array}$ & $\mathrm{N} / \mathrm{A}$ & $\mathrm{N} / \mathrm{A}$ & \\
\hline
\end{tabular}

Other incentives provided across Ontario show that the one-time study grant payouts do not produce the same impacts to investor returns as the one-time RDC exemption. Even when assuming the study-grant payout considered 100\% reimbursement of all site assessment costs (and not just those related to phase 1 and phase 2 ESA documents) the impacts and payouts are still less of the RDC exemption. This is because these one-time payouts are much smaller than the amount given in the $100 \%$ and $50 \%$ RDC exemption. However, according to the Region of Waterloo, the BFIP program approved 
more than 40 grants totalling over $\$ 30$ million. Assuming an average allocation of funds, the Region of Waterloo and Finance Minister may not approve a 100\% RDC exemption but potentially only a 50\% exemption. The tax assistance program offered in the first three years had small impacts to investor returns when compared to the TIEGS or RDC exemptions. The tax assistance program had a smaller impact because it covered the municipal (30\%) and school portion (16\%) of property taxes whereas Joint TIEGs were applied to both the municipal (30\%) and regional (54\%) portions of taxes. Furthermore, tax assistance funding could only be provided in the first three years of development when land values had not appreciated as much as they would have after development completion. TIEGS take effect directly after the development period and can be provided for a maximum of up to 10 years.

It is also important to note that three types of ClPs offered with brownfield provisions in Ontario were not included in our pro forma analysis. Façade Grants were not incorporated into the pro forma because the project is a new development and not an old building which requires exterior restoration. The Rehabilitation and Redevelopment grant could not be applied to the pro forma as well; these incentives do help with actual remediation figures (not just site analysis costs) by providing low interest loans to help overcome the high remediation and redevelopment costs. However, the loans being witnessed currently in Ontario and throughout Canada are at some of the lowest rates seen in the Bank of Canada's Historical Interest Rate Records (Bank of Canada, 2015). Finally, the municipal fees grant program involves one-time grants on certain permit and application fees; however, the true cost of the fees is negligible compared to the total project costs and would not constitute a meaningful change in a project's return.

It is also important to look at the best mix of incentives offered - after all, municipalities can offer a developer a wide range of incentives with brownfield provisions. The use of different CIPS together may impact our results differently than the individual impacts and need to be assessed. The 
coupling of different incentives will be applied according to specific rules and guidelines as stipulated under section 28 of the Planning Act, or also found in the MMAH Municipal Financial Incentives for Brownfield Redevelopment. The results from these couplings can be found in Table 10.

Table 10 - NPV and IRR changes for brownfield CIP packages

\begin{tabular}{|l|l|l|}
\hline CIP package & NPV (\$) & IRR (\%) \\
\hline $\begin{array}{l}\text { Waterloo BFTIP (Tax Assistance + } \\
\text { TIEGs) }\end{array}$ & $11,677,510.93$ & 14 \\
\hline $\begin{array}{l}\text { 100\% Full Study Grant (phase 1 } \\
\text { and phase2) + Tax Assistance } \\
\text { Program + TIEGs }\end{array}$ & $11,692,163.15$ & 14 \\
\hline $\begin{array}{l}\text { 100\% Full Study Grant (entire } \\
\text { site assessment costs) + Tax } \\
\text { Assistance Program + TIEGs }\end{array}$ & $11,723,001.14$ & 14 \\
\hline
\end{tabular}

The BFTIP (brownfields financial tax assistance program) uses both the tax assistance program and the TIEGs program. The TIEGs program is initiated when the tax assistance period ends, as stipulated by the MMAH Municipal Financial Incentives program for Brownfield Redevelopment (MMAH, n.d.). The other two incentive coupling packages involve both the tax assistance program as well as the TIEGs program with the addition of a full phase 1 or phase 2 ESA grant or with a full site assessment cost grant. According to the MMAH Municipal Financial Incentives for Brownfield Redevelopment programs, TIEGS or tax assistance cannot be used in conjunction with the RDC exemption; TIEGS and tax assistance typically offset other eligible remediation and redevelopment costs (MMAH, n.d.).

The brownfield redevelopment pro forma results indicate that the RDC exemptions provide the largest individual sensitivity factor for its impacts to both the NPV and IRR calculations. RDC exemptions, as a one-time grant payout, provide the largest increase to both NPV and IRR by $11.7 \%$ and $4 \%$ respectively. The RDC exemption calculation was determined by multiplying the total number of units in the building (132) by the residential development charges of $\$ 9836 /$ unit. This produced a one-time 
grant payout at the end of year 0 of $\$ 1,298,352$. Considering the Region of Waterloo had allocated $\$ 30$ million for over 40 grants, a single project receiving a grant of $\$ 1,298,352$ seems unreasonable. When applying the $50 \%$ RDC exemption, NPV and IRR calculations increased by $5.8 \%$ and $2 \%$ respectively. This $50 \%$ RDC exemption translates to a savings of $\$ 649,176$ which seems more reasonable and realistic to assume when considering the total amount of brownfield financial incentive funds being offered per project by the Region of Waterloo.

Joint TIEGS produced the next greatest individual impact on returns in our pro forma analysis increasing the feasibility of brownfield redevelopment. Here we can see that because TIEGS are extended over a longer time period (10 years as opposed to 3 years for tax assistance) and because the total amounts of the TIEGS in later years translates to more financial aid compared to the tax assistance program, TIEGs now represents our second largest sensitivity parameter. If for a particular project, the RDC exemption is limited to $50 \%$ or less, a Joint TIEG instrument will provide a greater NPV (increase of $6.7 \%$ is greater than $5.8 \%$ ) and the same IRR on equity of $14 \%$. If the investor is more concerned about weighing multiple different investment options, they might consider the NPV calculation to be more influential in making their decision. However, if an investor is only concerned about one investment opportunity as opposed to several, that investor or developer may be more concerned about the return they get on their investment (IRR on equity) and thus direct more consideration to the IRR calculations.

If RDC exemptions are limited to less than $50 \%$, Joint TIEGS may correspond to the best incentives offered in terms of their impacts on NPV and the IRR on equity. From the results of the pro forma, we can likely conclude that the one-time RDC exemption payouts will only impact investor returns more significantly than BFTIP programs if the developer can secure a $100 \%$ RDC exemption.

In determining the best mix-package of incentives available, any of the BFTIP coupling packages do not positively impact investor returns as much as the one-time $100 \%$ RDC exemption for both NPV 
and IRR on equity. Even when assuming the approval of a BFTIP package with a full site assessment recovery, this still translated into smaller impacts than an individual $100 \%$ RDC exemption. The coupling of a RDC exemption and BFTIP program was not possible; the by-laws for an RDC exemption state that the total funding is calculated by determining the allowable RDC exemption, less any previous funding available. RDC exemptions are viewed as up-front grants because they are offered early on in the development process, and even though financial tax assistance (BFTIP) is offered on a yearly basis after development completion, the municipality will still deduct these values because all grant submission forms must be submitted early in the development process (MMAH, n.d.).

The overall conclusion from the analysis is that if the RDC exemption is large enough, this sole CIP incentive option would translate into the greatest impact on investor returns (for both NPV and IRR). The following outcomes are also possible:

- If the RDC exemption is limited to 50\%, Joint TIEGS offered through the BFTIP would then be the most ideal individual incentive for helping to promote brownfield redevelopment.

- If the RDC exemption is limited to $50 \%$, the most ideal combined package in terms of its positive impacts to NPV and IRR would then be the BFTIP + Full Site Assessment Cost Recovery package. If coupling packages are approved by the Minister of Finance, this would be the most ideal incentive to target by policy makers to help promote brownfield redevelopment.

- If only individual incentives are approved, than the $100 \%$ RDC exemption would be the most influential incentive to target from a policy maker's viewpoint.

- The greenfield development projects is still the preferred method of development. This project generates the greatest returns with the lowest associated levels of risk from contamination. Greenfield development also lacks some of the institutional barriers to development such as the long duration of the regulatory process involved in brownfield redevelopment. 
Developers and investors are interested in projects with an expected IRR on equity return to that which is $12-15$ percentage points higher than the next safest alternative investment option. With an approved full RDC exemption, the brownfield redevelopment project fits into the acceptable range of returns. However when applying a worst case development scenario (where operating costs were arbitrarily increased to $40 \%$ and $50 \%$ of effective gross income) lower project returns were generated. This worst case scenario is taken into account in a developers mind as a precautionary measure for if operational costs increase. When operating costs represented $40 \%$ and $50 \%$ of effective gross income, the projects IRR on equity dropped to $9 \%$ and $5 \%$ respectively. NPV values also diminished with increased operational costs. As a result, developers and investors may look for a greater cushion of returns larger than the previously stated acceptable range. This would also lower the attractiveness of brownfield development further promoting greenfield developments.

The final research question considers the significance of these changes to investor returns and if they are substantial enough to promote brownfield redevelopment thus reducing development pressures on greenfields. It is quite clear that brownfield redevelopment entails greater costs than greenfield development, and as a result corresponds to a riskier investment option. Furthermore, greenfield development does not entail any past or future contamination liability, a figure which could not be quantified but is still ranked as one of the largest obstacles to brownfield redevelopment (De Sousa, 2000). The greenfield development did produce the largest IRR on equity at $17 \%$ and if investors and developers are solely concerned about the targeted levels of IRR on equity they wish to receive, than these incentives would not be strong enough factors to promote brownfield redevelopment over greenfield development. The greenfield development did however produce the lowest NPV, but this figure must be addressed carefully as the purchase price of the greenfield site did differ to that of the brownfield and we must thus compare the original purchase price to the expected NPV. The brownfield costed $\$ 1,500,000$ but produced a future NPV of $\$ 10,920,437.76$ (increase of $7.28 X$ ). The greenfield 
costed $\$ 625,000$ but produced a future NPV of $\$ 10,466,230.49$ (increase of $16.75 X)$. When applying the same cost for the greenfield pro forma as the brownfield site, the project still generated an IRR on equity of $17 \%$ and an NPV of $\$ 9,157,470.22$. From this viewpoint, an investor may still be more interested in the greenfield development option because although it generates a lower NPV, it still generates an IRR on equity of $17 \%$ and contains no associated levels of risk from contamination. In addition, greenfield development projects do not encounter the same regulatory process delays as brownfield remediation projects do which adds to the attractiveness of the greenfield development option. Thus, given the assumptions and results from the study, greenfield developments will continue to be a more attractive investment option compared to brownfield redevelopment even with individual and coupled incentive packages.

If policy makers are solely concerned about the effectiveness of the brownfield policy, then RDC exemptions and Joint TIEGS should be their primary focus as these incentives will produce the next largest impacts to investor and developer returns. The economic, social and environmental benefits from brownfield remediation do benefit all stakeholders including the government and the broader community. It is for these reasons that explains why governments should be incentivized to change their policy goals thus helping to reduce both the institutional and non-institutional barriers to brownfield redevelopment.

This research is novel because it provides a quantitative illustration of the direct impacts generated by the CIPs with brownfield provisions being offered in Ontario. The results show that in order to promote brownfield redevelopment as a form of sustainable development, policy makers should direct their attention mostly to the RDC exemption grant. If these grants are fully funded, this large one-time grant will provide a greater cushion for costs borne by developers and investors. If these impacts are large enough, and considered to be significantly important from the viewpoint of the 
developer or investor, brownfield remediation and redevelopment could be accelerated in secondary markets such as Waterloo, Ontario. If these RDC exemptions are limited to less than a 50\% coverage, Joint TIEG programs being offered over multiple years would produce the most significant impacts on investor returns and should thus be the primary focus for policy makers.

Most research on brownfield redevelopment focuses on the scientific and technical aspects; research on practical and applied matters of brownfield redevelopment are not as common. This research helps fill some of the gaps in the academic literature surrounding brownfield redevelopment by providing a quantitative (rather than qualitative) analysis of the true impacts of CIPs on investor returns. This research begs the need for more research in the field of brownfield redevelopment; further research could examine the impacts of other CIPs in other secondary markets across Ontario as well as other CIPs being offered in other provinces across Canada. These values could be compared to one another to gather a larger sample size of information on the true quantitative effectiveness of CIPs with brownfield provisions. Furthermore, these values could then be compared to incentive programs in other countries to see how effective their policy makers are at addressing the concerns of brownfield redevelopment. 


\section{Appendices}

Appendix 1: Brownfield Pro forma: No Incentives

\begin{tabular}{|c|c|c|c|c|c|c|c|c|}
\hline \multicolumn{9}{|c|}{ Brownfield Multifamily Residential - Hypothetical } \\
\hline & Year 0 & Year 1 & Year 2 & Year 3 & Year 4 & Year 5 & Year 6 & Year 7 \\
\hline Potential Gross Revenue & & & $\$ 1,579,248.00$ & $\$ 1,651,024.82$ & $\$ 1,726,063.90$ & $\$ 1,804,513.50$ & $\$ 1,886,528.64$ & $\$ 1,972,271.37$ \\
\hline Vacancy & & & $\$ 37,901.95$ & $\$ 39,624.60$ & $\$ 41,425.53$ & $\$ 43,308.32$ & $\$ 45,276.69$ & $\$ 47,334.51$ \\
\hline Effective Gross Income & & & $\$ 1,541,346.05$ & $\$ 1,611,400.23$ & $\$ 1,684,638.37$ & $\$ 1,761,205.18$ & $\$ 1,841,251.96$ & $\$ 1,924,936.86$ \\
\hline Operating Expenses ( $30 \%$ of EGI) & & & $\$ 462,403.81$ & $\$ 483,420.07$ & $\$ 505,391.51$ & $\$ 528,361.55$ & $\$ 552,375.59$ & $\$ 577,481.06$ \\
\hline Property Tax & $\$ 22,385.87$ & $\$ 22,721.66$ & $\$ 206,500.00$ & $\$ 209,597.50$ & $\$ 212,741.46$ & $\$ 215,932.58$ & $\$ 219,171.57$ & $\$ 222,459.15$ \\
\hline Net Operating Income & & & $\$ 872,442.23$ & $\$ 918,382.66$ & $\$ 966,505.39$ & $\$ 1,016,911.04$ & $\$ 1,069,704.80$ & $\$ 1,124,996.65$ \\
\hline Debt Service / Mortgage Payment & & & $\$ 709,706.52$ & $\$ 709,706.52$ & $\$ 709,706.52$ & $\$ 709,706.52$ & $\$ 709,706.52$ & $\$ 709,706.52$ \\
\hline Total Cash Flows & $-\$ 22,385.87$ & $-\$ 22,721.66$ & $\$ 162,735.71$ & $\$ 208,676.13$ & $\$ 256,798.87$ & $\$ 307,204.52$ & $\$ 359,998.27$ & $\$ 415,290.13$ \\
\hline
\end{tabular}

Appendix 2: Brownfield Sources and Uses of Funds: No Incentives

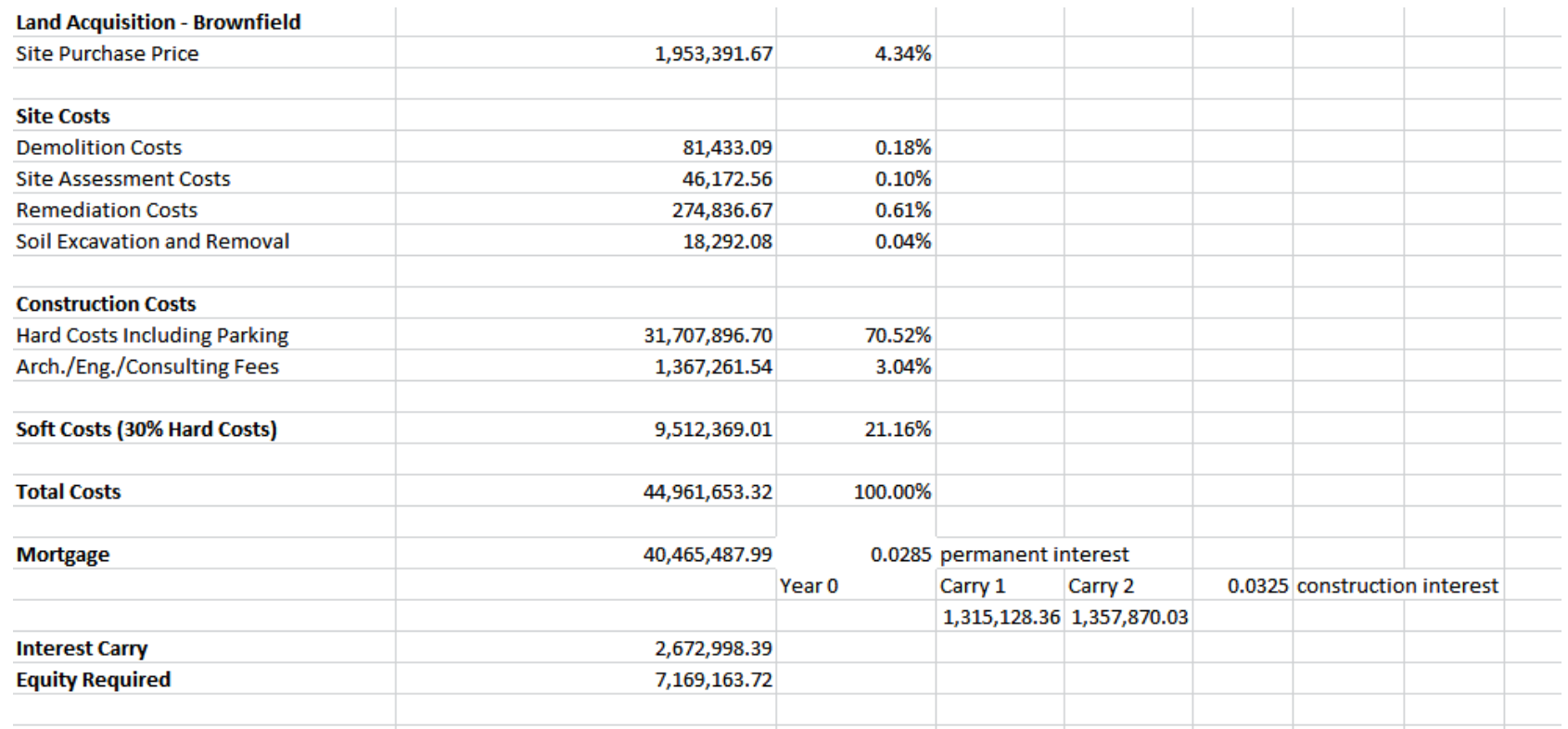

Appendix 3: Brownfield IRR and NPV: No Incentives

\begin{tabular}{|c|c|c|c|c|c|c|c|c|}
\hline \multicolumn{9}{|l|}{ IRR and NPV } \\
\hline & Year 0 & Year 1 & Year 2 & Year 3 & Year 4 & Year 5 & Year 6 & Year 7 \\
\hline Purchase Price & $-1,953,391.67$ & & & & & & & \\
\hline Cash Flow & $-22,385.87$ & $-22,721.66$ & $162,735.71$ & $208,676.13$ & $256,798.87$ & $307,204.52$ & $359,998.27$ & \\
\hline Sale Price (at end of year 6) & & & & & & & $23,684,140.06$ & \\
\hline Ending Mortgage Balance & & & & & & & $-10,706,570.79$ & \\
\hline Total Cash Flow & $-1,975,777.54$ & $-22,721.66$ & $162,735.71$ & $208,676.13$ & $256,798.87$ & $307,204.52$ & $13,337,567.54$ & \\
\hline Equity Investment + Total Flows & $-7,191,549.59$ & $-22,721.66$ & $162,735.71$ & $208,676.13$ & $256,798.87$ & $307,204.52$ & $13,337,567.54$ & \\
\hline \multicolumn{9}{|c|}{ Targeted Level IRR - Discount Rate $=1.5 \%$} \\
\hline NPV & $10,920,437.76$ & & & & & & & \\
\hline IRR & $12 \%$ & & & & & & & \\
\hline
\end{tabular}


Appendix 4: Brownfield Project Returns: No Incentives

\begin{tabular}{l|r|r|r|r|r|r|r|r|r|r|r|r|r|r|r|r|r|} 
& & \\
Returns & Year 0 & Year 1 & Year 2 & Year 3 & Year 4 & Year 5 & Year 6 & Year 7 \\
\hline Cash on Cash Return & & 0.023 & 0.029 & 0.036 & 0.043 & 0.050 & 0.058 \\
\hline Free and Clear Return (year 2. permanent financing valuation) & & 0.045 & 0.048 & 0.050 & 0.053 & 0.055 & 0.058 \\
\hline Free and Clear Return (development cost + acquisition) & & 0.019 & 0.020 & 0.021 & 0.023 & 0.024 & 0.025 \\
\hline Debt Coverage & & 1.229 & 1.294 & 1.362 & 1.433 & 1.507 & 1.585
\end{tabular}

Appendix 5: Greenfield Pro forma

\begin{tabular}{|l|r|r|r|r|r|r|}
\hline Proforma - Greenfield & & & & \\
& Year 2 & Year 3 & Year 4 & Year 5 & Year 6 & Year 7 \\
\hline Potential Gross Revenue & $1,579,248.00$ & $1,626,625.44$ & $1,675,424.20$ & $1,725,686.93$ & $1,777,457.54$ & $1,830,781.26$ \\
\hline Vacancy & $37,901.95$ & $39,039.01$ & $40,210.18$ & $41,416.49$ & $42,658.98$ & $43,938.75$ \\
\hline Effective Gross Income & $1,541,346.05$ & $1,587,586.43$ & $1,635,214.02$ & $1,684,270.44$ & $1,734,798.56$ & $1,786,842.51$ \\
\hline OPEX (30\% of EGI) & $462,403.81$ & $476,275.93$ & $490,564.21$ & $505,281.13$ & $520,439.57$ & $536,052.75$ \\
\hline Proprty Tax & $206,500.00$ & $209,597.50$ & $212,741.46$ & $215,932.58$ & $219,171.57$ & $222,459.15$ \\
\hline Net Operating Income & $872,442.23$ & $901,713.00$ & $931,908.35$ & $963,056.73$ & $995,187.42$ & $1,028,330.61$ \\
\hline Debt Service Payment & $-696,824.57$ & $-696,824.57$ & $-696,824.57$ & $-696,824.57$ & $-696,824.57$ & $-696,824.57$ \\
\hline Total Cash Flows & $175,617.67$ & $204,888.43$ & $235,083.79$ & $266,232.16$ & $298,362.85$ & $331,506.04$ \\
\hline
\end{tabular}

Appendix 6: Greenfield Sources and Uses of Funds

\begin{tabular}{|c|c|c|c|c|c|}
\hline \multicolumn{6}{|l|}{ Land Acquisition - Brownfield } \\
\hline Site Purchase Price & $625,000.00$ & & & & \\
\hline \multicolumn{6}{|l|}{ Site Costs } \\
\hline Demolition Costs & $81,433.09$ & & & & \\
\hline Site Assessment Costs & 0.00 & & & & \\
\hline Remediation Costs & 0.00 & & & & \\
\hline Soil Excavation and Removal & 0.00 & & & & \\
\hline \multicolumn{6}{|l|}{ Construction Costs } \\
\hline Hard Costs Including Parking & $31,707,896.70$ & & & & \\
\hline Arch./Eng./Consulting Fees & $1,367,261.54$ & & & & \\
\hline Soft Costs ( $30 \%$ Hard Costs) & $9,512,369.01$ & & & & \\
\hline Total Costs & $43,293,960.34$ & & & & \\
\hline \multirow[t]{3}{*}{ Mortgage } & 41129262.32 & 0.0285 & & & \\
\hline & & Year 0 & Carry 1 & Carry 2 & 0.0325 \\
\hline & & & 1336701 & 1380144 & \\
\hline Interest Carry & 2716844.834 & & & & \\
\hline Equity Required & $4,881,542.85$ & & & & \\
\hline
\end{tabular}


Appendix 7: Greenfield IRR and NPV

\begin{tabular}{|c|c|c|c|c|c|c|c|}
\hline \multicolumn{8}{|l|}{ IRR and NPV } \\
\hline & Year 0 & Year 1 & Year 2 & Year 3 & Year 4 & Year 5 & Year 6 \\
\hline Purchase Price & $-625,000.00$ & & & & & & \\
\hline Cash Flow & $-22,385.87$ & $-22,721.66$ & $175,617.67$ & $204,888.43$ & $235,083.79$ & $266,232.16$ & $298,362.85$ \\
\hline Sale Price (end of year 6) & & & & & & & $21,649,065.52$ \\
\hline Ending Mortgage Balance & & & & & & & $-10,512,234.73$ \\
\hline Total Cash Flow (including purchase price) & $-647,385.87$ & $-22,721.66$ & $175,617.67$ & $204,888.43$ & $235,083.79$ & $266,232.16$ & $11,435,193.64$ \\
\hline Equity + Total Flows & $-4,903,928.72$ & $-22,721.66$ & $175,617.67$ & $204,888.43$ & $235,083.79$ & $266,232.16$ & $11,435,193.64$ \\
\hline NPV & $10,466,230.49$ & & & & & & \\
\hline IRR & $17 \%$ & & & & & & \\
\hline
\end{tabular}

Appendix 8: Greenfield Project Returns

\begin{tabular}{|l|l|l|l|l|l|l|r|r|r|} 
Returns & & & & & & & \\
& Year 0 & Year 1 & Year 2 & Year 3 & Year 4 & Year 5 & Year 6 & \multicolumn{1}{l|}{ Year 7 } \\
\hline Cash on Cash Flow & & & 0.036 & 0.042 & 0.048 & 0.055 & 0.061 & 0.068 \\
\hline Debt Coverage & & & 1.252 & 1.294 & 1.337 & 1.382 & 1.428 & 1.476
\end{tabular}

Appendix 9: Waterloo Land Use Plan Schedule A

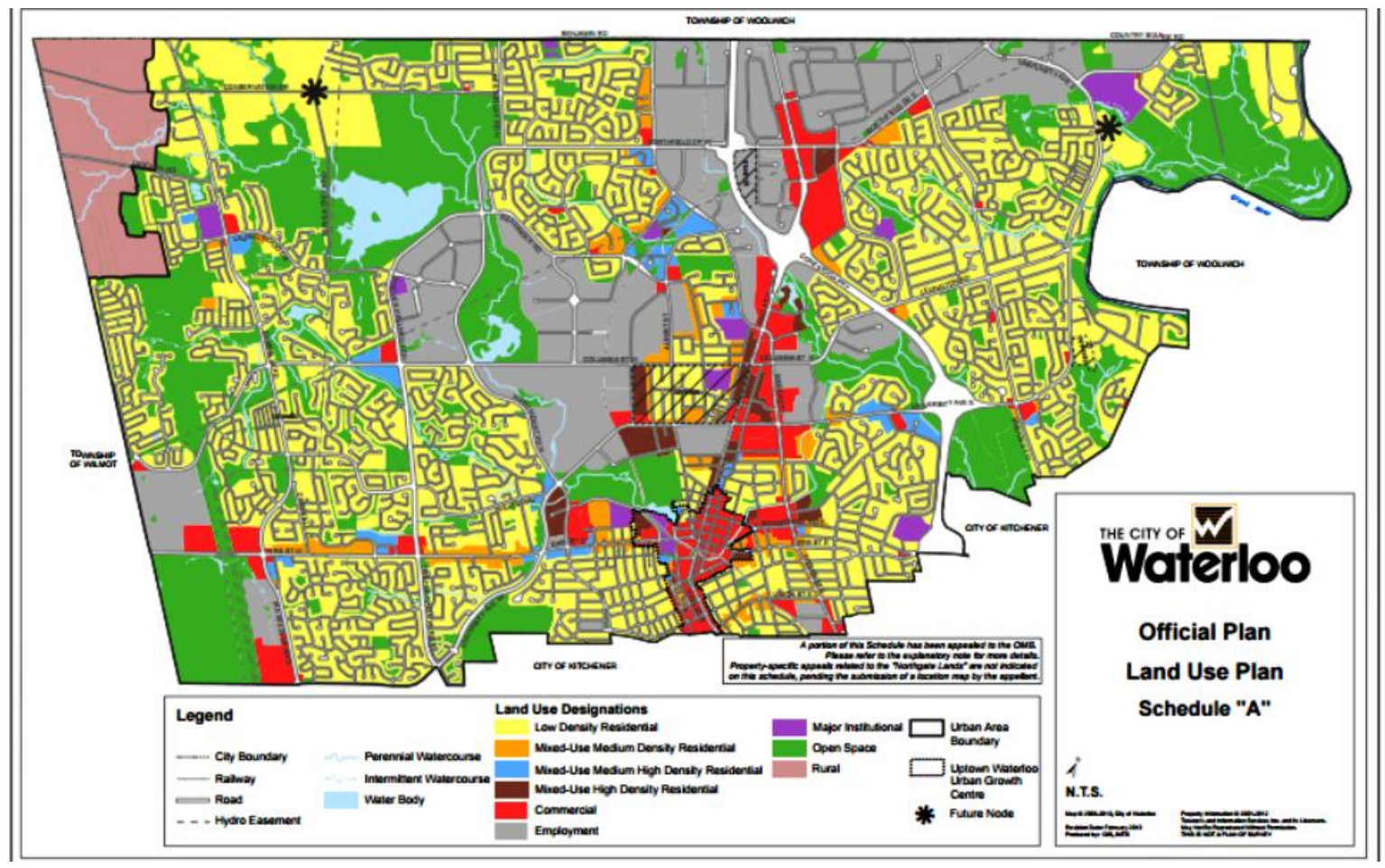

Source: (City of Waterloo, 2014) 


\section{Works Cited}

Bank of Canada. (2016). Canadian Bond Yields: 10-Year Lookup. Retrieved 2016, from Bank of Canada : http://www.bankofcanada.ca/rates/interest-rates/lookup-bond-yields/

Begley, J. (2014). Lecture 04 Class Notes. Toronto : Ryerson University .

Canadian Council of Ministers of the Environment . (2008). National Classification System for Contaminated Soils Guidance Document. Winnipeg : Canadian Council of Ministers of the Environment .

Canadian Council of Ministers of the Environment. (1996). A framework for Ecological Risk Assessment: General Guidance. Manitoba: Canadian Council of Ministers of the Environment.

Canadian Council of Ministers of the Environment. (1997). Guidance Document on the Management of Contaminated Sites in Canada. Canadian Council of Ministers of the Environment.

Canadian Council of Ministers of the Environment. (1999). Guidance Manual for Developing Site-Specific Soil Quality Remediation Objectives for Contaminated Sites in Canada. Canadian Council of Ministers of the Environment.

CBRE Limited. (2015). CBRE Marketview; Canada Multifamily, H1 . CBRE Research.

CBRE Limited. (2016). CBRE Marketview; Canada Investment, Q4. CBRE Research.

CBRE Limited. (2016). CBRE Marketview; Canada Multifamily, H2. CBRE Research.

City of Kitchener and Region of Waterloo. (2013). Brownfields Financial Incentive Program Joint Tax Increment Grant Application Package. Waterloo: Region of Waterloo.

City of Waterloo. (2011). Waterloo Region Profile; Statistics, Trends \& Forecasts Towards Understanding Implications for the Future. Waterloo: City of Waterloo.

City of Waterloo. (2014). Official Plan City of Waterloo. Waterloo: City of Waterloo.

De Sousa, C. (2015). Overcoming barriers and facilitating brownfields redevelopment in the GTHA: A review of results from interviews with private sector stakeholders.

De Sousa, C. A. (2000). Brownfield Redevelopment versus Greenfield Development: A Private Sector Perspective on the Costs and Risks Associated with Brownfield Redevelopment in the Greater Toronto Area. Journal of Environmental Planning and Management, 831-853.

De Sousa, C. A. (2002). Brownfield redevelopment in Toronto: an examination of past trends and future prospects. Land Use Policy, 297-309.

De Sousa, C. A. (2002). Measuring the public costs and benefits of brownfield versus greenfield development in the Greater Toronto Area. Environment and Planning B: Planning and Design, $29,251-280$. 
De Sousa, C. A. (2006). Urban brownfields redevelopment in Canada: the role of local government. The Canadian Geographer, 392-407.

Government of Canada. (2015, November 3). The Action Plan History. Retrieved April 2016, from Federal Contaminated Sites Portal : http://www.federalcontaminatedsites.gc.ca/default.asp?lang=En\&n=F5358597-1

Henriques, I., \& Sadorsky, P. (2013). Environmental Management Practices and Performance in Canada. Canadian Public Policy, 39, 157-175.

Marr, W. L. (2015, 03 04). Industrialization. Retrieved May 2016, from The Canadian Encyclopedia: http://www.thecanadianencyclopedia.ca/en/article/industrialization/

Meyer, P. B., \& Lyons, T. S. (2000). Lessons from Private Sector Brownfield Redevelopers . American Planning Association , 66, 46-57.

Ministry of Municipal Affairs and Housing . (2014). Provincial Policy Statement . Toronto : Ministry of Municipal Affairs and Housing .

Ministry of Municipal Affairs and Housing. (2007). A Practical Guide to Brownfield Redevelopment in Ontario. Queen's Printer for Ontario.

Ministry of the Environment. (2011). Soil, Ground Water and Sediment Standards for Use Under Part XV.1 of the Environmental Protection Act. Minstry of the Environment.

Ontario Government . (2001, November). Brownfields Statute Law Amendment Act, 2001. Retrieved 2015, from Ontario Government : https://www.ontario.ca/laws/statute/S01017

Ontario Government. (2016, May 18). Environmental Protection Act. Retrieved 2015, from Ontario Government : https://www.ontario.ca/laws/statute/90e19

Ontario Ministry of Municipal Affairs and Housing . (n.d.). Municipal Financial Incentives for Brownfield Redevelopment: Trends among Ontario Municipalities . Ontario Ministry of Municipal Affairs and Housing .

Ontario Ministry of the Environment . (1992). Guidelines for the Decomissioning and Cleanup of Sites in Ontario . Queen's Printer for Ontario .

Ontario Ministry of the Environment . (2004). Records of Site Condition: A Guide on Site Assessment, the Cleanup of Brownfield Sites and the Filing of Records of Site Condition . Queen's Printer for Ontario .

Ontario Ministry of the Environment. (2012). Records of Site Condition \#204488. Waterloo: Ontario Ministry of the Environment .

Ontario Ministry of the Environment. (2014). Records of Site Condition \#211952. Waterloo : Ontario Mniistry of the Environment . 
Ontario Ministry of the Environment. (2014). Records of Site Condition \#212608. Waterloo : Ontario Ministry of the Environment .

Ontario Ministry of the Environment. (2014). Recrods of Site Condition \#213109. Waterloo : Ontario Ministry of the Environment.

Ontario Ministry of the Environment and Climate Change . (2015). Records of Site Condition \#217746. Waterloo : Ontario Ministry of the Environment and Climate Change .

Peiser, R., \& Hamilton, D. (2012). Professional Real Estate Development: The ULI Guide to the Business. Urban Land Institute.

Region of Waterloo. (2016). Brownfield Financial Incentives Program Eligible Remediation Cost Submission Requirements. Waterloo: Region of Waterloo.

Region of Waterloo. (2016). Regional Development Charges Information Brochure. Waterloo: Region of Waterloo.

Sheppard, S. C., Gaudet, C., Sheppard, M. I., Cureton, P. M., \& Wong, M. P. (1992). The development of assessment and remediation guidelines for contamined soils, a review of the science. Canadian Journal of Soil Science, 72, 359-394.

Smith, D. W., Member, ASCE, \& Stanley, S. J. (1995). Development of Cleanup Protocol for Contaminated Sites in Canada. Journal of Professional Issues in Engineering Education and Practice, 121, 67-70.

Statistics Canada. (2015, November 27). NHS Profile, Kitchener - Cambridge - Waterloo, CMA, Ontario, 2011. Retrieved 2016, from Statistics Canada: https://www12.statcan.gc.ca/nhs-enm/2011/dp$\mathrm{pd} /$ prof/details/page.cfm?Lang=E\&Geo1=CMA\&Code1=541\&Data=Count\&SearchText=Kitchene r\%20-\%20Cambridge\%20-

\%20Waterloo\&SearchType=Begins\&SearchPR=01\&A1=All\&B1=All\&GeoLevel=PR\&GeoCode=541 \&TABID=1

Statistics Canada. (2016, January 22). Canada Mortgage and Housing Corporation, housing starts, under construction and completions in centres 10,000 and over, Canada, provinces, selected census metropolitan areas . Retrieved 2016 , from Statistics Canada:

http://www5.statcan.gc.ca/cansim/a26

Statistics Canada. (2016, January 07). Focus on Geography Series, 2011 Census. Retrieved 2016, from Statistics Canada: https://www12.statcan.gc.ca/census-recensement/2011/as-sa/fogsspg/Facts-cma-eng.cfm?LANG=Eng\&GK=CMA\&GC $=541$ 


\section{Glossary / Key Words}

Brownfield: Lands that are potentially contaminated due to historical, industrial or commercial land use practices, and are underutilized, derelict or vacant.

Brownfields Financial Tax Incentive Program (BFTIP): A tax assistance program with brownfield provisions, such that both tax assistance and tax increment equivalent grants can be used as a form of a CIP to help promote brownfield redevelopment for a specified time period.

Brownfield Redevelopment: A form of sustainable development that emphasizes the re-use of existing developed lands rather than developing on greenfields.

Canadian Council of Ministers of the Environment (CCME): CCME is the primary minister-led intergovernmental forum for collective action on environmental issues and is comprised of environmental ministers from the federal, provincial and territorial governments.

Capitalization Rates (CAP): The ratio of Net Operating Income (NOI) to property asset value. Also known as the rate of real return on a real estate investment property based on the income that the property is expected to generate.

Community Improvement Plans (CIPs): Plans that focus on the maintenance, rehabilitation, development or redevelopment for a specific community. Community Improvement Plans with Brownfield provisions will produce different incentive measures offered by the community to promote the remediation and rehabilitation of brownfield sites within that community.

Environmental Site Assessment (ESA): This includes both Phase 1 and Phase 2 Environmental Site Assessments. Phase 1 assessments determine the type of contamination present (if any), while Phase 2 assessments illustrate the remediation necessary for the types of contaminants found in the Phase 1 Assessment.

Federal Contaminated Sites Action Plan (FCSAP): Initiated in 2005 by the Government of Canada, this program gathers and produces reports which provide the current potential risk to human health and the environment from contaminated sites.

Greenfield: Agricultural lands that have not yet been subjected to developmental pressures.

Multifamily Development: This refers to both condominium and apartment type developments which house multiple families.

National Classification System for Contaminated Sites (NCSCS): A report released by the CCME to aid in classifying sites based on their current potential risks posed to human health and the environment. This 5-step system established a convenient basis for assessing site-specific contamination on a ranking basis. 
National Contaminated Sites Remediation Program (NCSRP): Program responsible for remediating federal orphaned contaminated sites of high risk while also promoting environmental technology for site remediation.

National Round Table on the Environment and Economy (NRTEE): Independent federal affiliated agency responsible for policy advice to raise awareness about the challenges of sustainable development to the Government of Canada and its citizens.

Ontario Ministry of Municipal Affairs and Housing (MMAH): Provincial affiliated agency with the Government of Ontario that works with the community and private stakeholders to support local governments in their planning and management of a community's future and to provide a full range of housing needs that protect homeowners and encourage private development.

Pro forma: An accounting style projection of a projects cash flow used by developers to determine the feasibility of different development project options. Also commonly known as a development appraisal.

Records of Site Condition (RSC): Records of Site Condition documents provide an analysis on site characteristics and must be submitted for every development project where land-use changes to a more sensitive environment (going from industrial to residential).

Regional Development Charges (RDC): A tool to help promote brownfield redevelopment in a CIP by exempting all or part of the development charges related to the applicable development project.

Tax Assistance: The tax assistance program refers to a tax incentive offered in the CIP and is summarized as the deferral or cancelation of the municipal and/or school portions of property tax.

Tax Increment Equivalent Grants (TIEGS): The tax increment equivalent grants, also known as TIEGS, is summarized as another incentive part of a CIP offering financial assistance to offset either a portion or all of the municipal property tax increase from pre development to post development property taxes. 